\title{
Insights From Principal Component Analysis Applied to Py- GCMS Study of Indian Coals and Their Solvent Extracted Clean Coal Products
}

\author{
Abyansh Roy \\ Indian Institute of Technology Delhi \\ Heena Dhawan \\ Indian Institute of Technology Delhi \\ Sreedevi Upadhyayula ( $\sim$ sreedevi@chemical.iitd.ac.in ) \\ Indian Institute of Technology Delhi \\ Hariprasad Kondamana \\ Indian Institute of Technology Delhi
}

\section{Research}

Keywords: Coal, Super clean coals, Pyrolysis, PCA, ATR-FTIR, Py-GCMS

Posted Date: December 17th, 2020

DOI: https://doi.org/10.21203/rs.3.rs-127356/v1

License: (a) This work is licensed under a Creative Commons Attribution 4.0 International License. Read Full License

Version of Record: A version of this preprint was published at International Journal of Coal Science \& Technology on August 21st, 2021. See the published version at https://doi.org/10.1007/s40789-021-00457-x. 


\section{Abstract}

The present work aims at studying five Indian coals and their solvent extracted clean coal products using Py-GCMS analysis and correlating these characterizations with results from theoretical a principal component analysis. The pyrolysis products of the original coals and the super clean coals were classified as mono-, di and tri- aromatics while other prominent products that were obtained included cycloalkanes, $n$-alkanes and alkenes ranging from $\mathrm{C}_{10}-\mathrm{C}_{29}$. The Py-GCMS results for the samples were studied using Principal Component Analysis. Inferences on relative composition of constituent compounds and functional groups and structural insights based on scores and loading plots of the PCA analysis were consistent with the experimental observations. ATR-FTIR studies confirmed the reduced concentration of ash in the super clean coals and the presence of aromatics. The PyGCMS data and the ATR-FTIR spectra led to the conclusion that the super clean coals behaved similarly for both coking and noncoking coals with high aromatic concentrations as compared to the raw coal. Neyveli lignite super clean coal was found to show some structural similarity with the original coals, whereas, the other super clean coal showed structural similarity among them but not with their original coals indicative of the selective action of the e, $\mathrm{N}$ solvent system on the polycondensed aromatic structures in coal.

\section{Introduction}

Pyrolysis has been used to produce fuels and oils that have characteristics such as high energy density and low volatility. There are various reactions involved in the pyrolysis of fossil fuels and biomass such as aromatization, hydrogen transfer, oligomerization and de- oxygenation, many of these reactions producing aromatics. The product slate formed during pyrolysis includes liquid (oil), gases, water, char and coke (Huber et al. 2006). A variety of analytical techniques such as Fluorescence Spectroscopy, Mass Spectrometry (MS), High Performance Liquid Chromatography (HPLC), and Infrared Spectroscopy (IR) is typically used to analyse the complex mixture of hydrocarbons formed and their derived products (De Lira et al. 2010; Molina et al. 2010; Mullins 2010)

Solvent extraction of coal has well been explored in the past (Van Krevelen 1993; Sharma and Dhawan 2018). The production of clean coal using varied solvents has led to recovery of Super Clean Coals (SCCs), Ultra-Clean Coals (UCCs) and Ultra-Super Clean Coals (U-SCCs) with negligible or no ash content. Hypercoal production is a recent development that uses two-ring aromatic solvents like tetralin and 1-Methylnaphthalene (1-MN) with which extraction of $70 \mathrm{wt}$ \% of bituminous coals is possible at elevated temperatures and high pressures (Okuyama et al. 2004; Masayuki et al. 2011). Solvent extraction of coals and the analysis of their clean products through pyrolysis and Py-GCMS is an area gaining in importance (Fujitsuka et al. 2013; Yan et al. 2014; Zhang et al. 2016). Thermogravimetric analysis (TG) and Fourier Transform Infrared (FTIR) analysis of evolved products have also been successfully used for characterization of heavy hydrocarbons, rocks, coals, biomass, waste materials, plastics, etc. FTIR provides insights into the pyrolysis of coals, including the kinetics of functional-group decomposition. The elements and functional groups of coal tar closely resemble coal and typical macromolecular debris of coal. Therefore, methods typically applied to the analysis of coal can help in revealing information about the composition of heavy hydrocarbon liquids.

Pyrolysis reactions are complex and require a better understanding through the study of reaction networks, kinetics and mechanisms. In this context Py-GCMS is a particularly useful analytical method and can be used semi-quantitatively to identify volatile products. The coal tar generated can prove to be a useful product to derive a lot of useful information. Coal tar contains chemical compounds that are very valuable commercially and industrially. These include aromatic compounds (benzene, toluene, xylene, naphthalene, anthracene, etc.), phenolic compounds (phenol, cresol, xylenol, cathecol, resorcinol, etc.), heterocyclic nitrogen compounds (pyridine, quinolone, isoquinoline, indole, etc.) and oxygen heterocyclic compounds (Fardhyanti 2015). The composition of coal tar varies with its origin and type of coal (for example lignite, bituminous coal, or anthracite) used in its production. Therefore, a more advanced data analysis technique could help in revealing more insights from the experimental data sets. In this work, we employ a combination of Principal Component Analysis (PCA) and Gaussian Mixture Modeling (GMM) for detailed data analysis and further categorization of these compounds.

PCA is a statistical analysis that helps the study and categorization of a large number of possibly interrelated parameters, which are used as variables, into a smaller number of uncorrelated variables called principal components. This technique is proving to be very useful in extracting relevant inferences from complex data sets as it reduces a large set of variables into a smaller set

Page $2 / 28$ 
without significant loss of the information. Indeed, PCA is a widely used technique for the analysis of multivariate Py-GC/MS data (Meier et al. 2005; Schwarzinger 2005; Pattiya et al. 2010). PCA has also been used for the characterization and classification of a number of coals based on the differences in their properties such as particle size, density, ash contents (Niedoba 2014). A database for 44 brown coals has been studied extensively by Tesch and Otto (Tesch and Otto 1995) to derive co-relations between several chemical, technological and IR spectroscopic parameters and the principal component analysis helped explain the data or categorize the coals. Additional components were required to be included to derive more information from the data. Three Canadian coals upgraded through evaporative drying up to $500^{\circ} \mathrm{C}$ were studied by Friesen and Ogunsola using PCA (Friesen and Ogunsola 1994). The lignite showed variation in its tar structure above $400{ }^{\circ} \mathrm{C}$ whereas other two bituminous and sub-bituminous coals above $300^{\circ} \mathrm{C}$. No significant difference was found in the structure of the upgraded coals as compared to the original coals.

In the present study, PCA analysis was applied to identify, categorize and compare the data sets of five original coals (OCs) and their SCCs. PCA analysis was used to statistically study the nature and the relative concentrations of the aromatics, aliphatics, alkenes, etc., formed during pyrolysis of the original coals and was used to compare them with their solvent extracted clean products. GMM (Gaussian Mixture Model) algorithm is used along with PCA for identification and quantitative characterization of clusters in the plot. It facilitates better visualization of spread of samples in space and statistical analysis of local features in the data.

\section{Experiment}

\subsection{Samples and Geological Setting}

Five Indian coal samples - Bhagabandh coal, Moonidih coal, Pandra coal, Bahula coal, Neyveli Lignite -were procured from NTPC power station, New Delhi and the Ministry of Coal, Govt. of India. Neyveli lignite was procured from Neyveli Lignite Corporation. Tables S1 and S2 (Supplementary Data) show the proximate and ultimate analysis of the samples. The samples were dried and extracted with $\mathrm{N}$-methyl pyrrolidone containing a small amount of ethylenediamine. The procedure reported by Dhawan et al. (Dhawan and Sharma 2019) was used for the recovery of the SCCs. The extraction yields of the coals and the ash contents in the SCCs are given in Table S3 (Supplementary Data).

\subsection{ATIR-FTIR Spectra}

The ATR-FTIR spectral analysis of the raw (OC), residual (coal left after the extraction of SCC) and SCC was performed using Nicolet 6700 Infra-Red Spectrometer. ATR-FTIR spectra were recorded in the range $4000-600 \mathrm{~cm}^{-1}$ using a Ge crystal with a resolution of $4 \mathrm{~cm}^{-1}$ with 32 scans (Odeh 2015; Dhawan and Sharma 2019).

\subsection{Py-GCMS Analysis}

Py-GCMS experiments were performed using a Pyroprobe Model 5200 (CDS Analytical, Inc.) connected to an Agilent 7890 GC with an Agilent 5975C MS detector. The pyroprobe was run in trap mode under He atmosphere. Pyrolysis was conducted at $650^{\circ} \mathrm{C}$ $\left(1,000{ }^{\circ} \mathrm{C} / \mathrm{s}\right.$ heating rate) for $20 \mathrm{~s}$. The valve oven and transfer lines were maintained at $325^{\circ} \mathrm{C}$. The column used in the GC was a DB1701 (60 $\mathrm{m} \times 0.25 \mathrm{~mm} \times 0.25 \mu \mathrm{m}$ ), and the temperature program was as follows: $45^{\circ} \mathrm{C}$ for $3 \mathrm{~min}$, ramp to $280{ }^{\circ} \mathrm{C}$ at $4{ }^{\circ} \mathrm{C} / \mathrm{min}$, and hold for $10 \mathrm{~min}$. The flow rate was set to $1 \mathrm{~mL} / \mathrm{min}$ using He as the carrier gas. The inlet and auxiliary lines were both maintained at $300{ }^{\circ} \mathrm{C}$, and the MS source was set at $70 \mathrm{eV}$. The GC-MS was calibrated for a number of phenolic compounds including phenol, 2-methoxyphenol, 2-methoxy-4-methylphenol, 2,6-dimethoxyphenol, vanillin, syringe aldehyde, and 2-methoxy-4-vinylphenol. Pyrolysis products were analyzed according to retention times and mass spectra data obtained from a NIST library.

One milligram of the ground $(45-150 \mu \mathrm{m})$ coal (raw and SCCs) was analyzed in a quartz cell packed with quartz wool. Samples were heated to $100^{\circ} \mathrm{C}$ for $10 \mathrm{sec}$. in the probe prior to analysis in order to remove any residual water. Prior to sample analysis, blank experiments were performed in order to validate the cleanliness of the system. After sample analysis, methanol was run as a sample to remove any condensed products inside the pyroprobe. Methanol and blank experiments were repeated as necessary until the system was clean (Harman-Ware et al. 2015). All experiments were performed 3 times and the average values are reported. 


\subsection{Data Analysis}

Principal Component Analysis was carried out using MATLAB's Statistics and Machine Learning Toolbox. After clubbing compounds into groups of aromatics and aliphatics, PCA was carried out with sum of peak area percentages of compounds (belonging to that particular group) as variables/dimensions for the ten coal samples-five original (OC) and five supercleaned (SCCs). A particular type of coal say Neyveli lignite would have its own original and super cleaned variants. The principal components were obtained by eigen value decomposition of data covariance matrix. The principal subspace is defined by the eigen vectors corresponding to the largest eigen values retained. Here, the data is presented with two principal components (PC1 and PC2) and thus, effective dimensionality of data gets reduced to two. Scores and Loadings plot are referred together to analyze the results with the former depicting the relative position of samples on the plane with PC1 and PC2 as abscissa and ordinate

respectively. GMM algorithm was used for determining cluster characteristics, i.e. cluster mean and covariance matrix. It was used to identify the clusters of super cleaned and original coals on the 2D plane with PC1 and PC2 as axes. Contour plots represent the stretch of clusters and spread of data points inside it.

\section{Results And Discussions}

\subsection{ATR-FTIR Spectra Analysis}

ATR-FTIR spectra for all coal samples verified the PCA analysis. Bands that are present between $1100-600 \mathrm{~cm}^{-1} \mathrm{correspond} \mathrm{to}^{-1}$ mineral matter such as illite, montmonrollite, quartz and aluminosilicates. The band specifically around $1030 \mathrm{~cm}^{-1}$ shows the presence of Si-O bonds (ash) in the system. The raw coal and residue clearly show the presence of ash, whereas the intensity of the band around $1030 \mathrm{~cm}^{-1}$ diminishes in the SCCs (Balachandran 2014). The aromatic absorption bands at 750 and $815 \mathrm{~cm}^{-1}$ in the raw coals and the SCCs are due to out-of-plane vibrations of one isolated and two adjacent $\mathrm{C}-\mathrm{H}$ aromatic groups, respectively (Table I). The spectra of the SCCs showed one such aromatic band at $750 \mathrm{~cm}^{-1}$. Absorption bands at $1600 \mathrm{~cm}^{-1}$ in SCCs are attributed to the presence of $\mathrm{C}=\mathrm{C}$ stretching accentuated due to $\mathrm{H}$-bond containing functional groups (Table $\mathrm{I}$ ) (Cooke et al. 1986). These aromatic bands were found to be more intense in SCCs showing effective action of the e, $\mathrm{N}$ solvent in coal cleaning (Sun et al. 2011).Pandra coal shows an increase in aromatics, especially triaromatics while, Bhagabandh shows increase in diaromatics and triaromatics, which is also evident by the increase in the $\mathrm{H}_{\mathrm{ar}} / \mathrm{H}_{\mathrm{ali}}$ ratio.

\subsection{Py-GCMS and PCA of OCs and SCCs}

\subsubsection{Py-GCMS}

Py-GCMS studies were performed for the five coals and their solvent extracted SCCs. The basic characterization of these coals (Elemental, proximate analysis, TG curve) is already reported by the authors (experimentalists in this group, Dhawan et al.) in a previous published work (Sharma et al. 2019).

Table I Structural parameters deduced from the FTIR peak area measurements 


\begin{tabular}{|c|c|c|c|c|c|c|c|c|c|}
\hline Coal & $\mathrm{H}_{\mathrm{ar}} / \mathrm{H}_{\mathrm{ali}}$ & $\begin{array}{l}\mathrm{H}_{\mathrm{ar}}(\mathrm{wt} \%) \\
(2700- \\
3000 \\
\left.\mathrm{~cm}^{-1}\right)\end{array}$ & $\begin{array}{l}\mathrm{H}_{\mathrm{ali}}(\mathrm{wt} \%) \\
(700- \\
\left.900 \mathrm{~cm}^{-1}\right)\end{array}$ & $\begin{array}{l}\mathrm{C}_{\mathrm{ar}}(\mathrm{wt} \%) \\
(1600- \\
1800 \\
\left.\mathrm{~cm}^{-1}\right)\end{array}$ & $\begin{array}{l}\mathrm{C}_{\mathrm{ali}}(\mathrm{wt} \%) \\
(1375- \\
1450 \mathrm{~cm}^{-1}, \\
2850- \\
2990 \mathrm{~cm}^{-} \\
1)\end{array}$ & $\mathrm{C}_{\mathrm{ar}} / \mathrm{C}_{\mathrm{al}}$ & $\begin{array}{l}-C=0 \\
(w t \%) \\
(2695- \\
2830 \\
\left.\mathrm{~cm}^{-1}\right)\end{array}$ & $\begin{array}{l}\mathrm{CH}_{3} \text { (deformation) } \\
\left(1300-1400 \mathrm{~cm}^{-1}\right)\end{array}$ & $\mathrm{H}_{\mathrm{ar}} / \mathrm{C}_{\mathrm{ar}}$ \\
\hline $\begin{array}{l}\text { Bhagabandh } \\
\text { OC }\end{array}$ & 1.34 & 8.03 & 5.99 & 6.23 & 6.20 & 1.00 & 4.32 & 2.95 & 1.28 \\
\hline $\begin{array}{l}\text { Bhagabandh } \\
\text { SCC }\end{array}$ & 1.55 & 9.29 & 5.98 & 6.82 & 5.73 & 1.19 & 3.78 & 2.55 & 1.36 \\
\hline Bahula OC & 1.35 & 7.95 & 5.87 & 5.71 & 6.21 & 0.92 & 4.09 & 2.98 & 1.39 \\
\hline Bahula SCC & 1.59 & 9.23 & 5.77 & 5.93 & 5.98 & 0.99 & 3.93 & 2.63 & 1.55 \\
\hline $\begin{array}{l}\text { Moonidih } \\
\text { OC }\end{array}$ & 1.46 & 8.45 & 5.76 & 6.12 & 5.97 & 1.02 & 3.84 & 3.65 & 1.38 \\
\hline $\begin{array}{l}\text { Moonidih } \\
\text { SCC }\end{array}$ & 1.66 & 9.71 & 5.83 & 5.75 & 6.21 & 0.93 & 3.90 & 3.07 & 1.68 \\
\hline Pandra OC & 1.43 & 9.46 & 6.59 & 6.90 & 7.72 & 0.89 & 4.66 & 14.34 & 1.37 \\
\hline Pandra SCC & 1.58 & 9.50 & 5.99 & 5.79 & 7.28 & 0.79 & 3.84 & 3.00 & 1.64 \\
\hline NL OC & 1.53 & 8.76 & 5.74 & 5.85 & 5.93 & 0.98 & 3.54 & 3.00 & 1.50 \\
\hline NL SCC & 1.47 & 8.82 & 5.97 & 6.30 & 7.01 & 0.89 & 3.74 & 2.95 & 1.4 \\
\hline
\end{tabular}

Each sample gave rise to more than 50 identifiable chemical compounds during pyrolysis. The compounds were categorized according to triaromatics, diaromatics, monoaromatics, cycloalkanes, n-alkanes, alkenes and other structures based on matches with the NIST mass spectral library. The main aliphatic compounds present in the coal tar (i.e., pyrolysis vapour) were paraffin hydrocarbons, while the main aromatic components were monoaromatics such as benzene, toluene, o-xylene, phenols and substituted phenols. Polycyclic aromatic hydrocarbons (PAHs) that were identified included naphthalene, substituted naphthalenes, phenanthrene, substituted phenanthrenes, anthracene, pyrene, etc, with naphthalene and its derivatives constituting the main constituents. The coal tar also contained some oxygen compounds, such as acids, and small amounts of aromatics containing nitrogen (Makan et al. 2017).

The mass spectra of the whole sample (OCs and SCCs) pyrolysis vapors show a complex series of ions ranging from $\mathrm{m} / \mathrm{z} 100$ to $\mathrm{m} / \mathrm{z} 450$, indicating the presence of polyaromatics such as fluoranthene and pyrene. Other significant products that were obtained through the analysis of the NL OC were methylpyrenes ( $\mathrm{m} / \mathrm{z} 216)$, methyl phenol (m/z 220) and toluene ( $\mathrm{m} / \mathrm{z}$ 92) and in NL SCC, a high intensity of $\mathrm{m} / \mathrm{z} 220$ and higher alkenes was observed.

An intense anthracene signal ( $\mathrm{m} / \mathrm{z}$ 178) was observed for Pandra SCC while the product mixture from Pandra OC was mainly dominated by alkanes and alkenes (Fig. 2). An intense signal corresponding to o-xylene (m/z 106) was observed in the case of both Moonidih OC and SCC (Fig. 3). Alkane peaks from C17 to C28are observed at the end of the chromatogram. The narrow peaks (for $\mathrm{C} 17$ to $\mathrm{C} 28$ alkanes and alkenes) vary from coal to coal, showing higher intensity in the case of high ash Pandra coal and low intensity in the case of low ash Bhagabandh and Moonidih coals (Fig. 2 \& 3). Toluene was found to be a major product from Bahula OC. Indeed, in general the OCs were found to be good sources of monoaromatics such as benzene, toluene and o-xylene (Islas et al. 2000).

Average aromatic content in the Moonidih OC is marginally higher than the corresponding SCC (Fig. 3). In the case of the other four coals studied - Pandra coal (high ash non-coking coal), Bahula coal (high ash non-coking coal), Bhagabandh coal (low ash coking coal) and Neyveli lignite (low ash lignite), the average content of the aromatics in SCCs as compared to OCs is higher than 
the aliphatics. Aromatics larger than naphthalene could have been formed from char or some other non-volatile products during the pyrolysis process or through numerous reactions involving alkylated derivatives (Sharma et al. 2019).

As explained by Radenovic (Rađenović 2006), the pyrolysis conditions result in the formation of free radicals via the cleavage of associations between the primary and secondary units of the condensed polyaromatic coal macromolecular network.

The SCCs obtained were found to have more volatile matter (VM) and easily degradable units compared to the OCs, resulting in increased tar formation from the SCCs. The various reactions that result in tar formation include depolymerisation, dehydrogenation, decarboxylation, hydrogenation and the stabilization of the heavy weight compounds obtained through secondary cracking reactions from the primary structure of coal. Thus, some information could be derived about the action of the e,N solvent system (NMP containing a small amount of EDA) studied through the Py-GCMS analysis of the samples. NMP, a polar diprotic solvent that has a good affinity for aromatics, is widely used in petroleum refineries. EDA has been found to be a good coal swelling and extracting solvent through the breaking of hydrogen bonds (Pande 2000; Pande and Sharma 2001, 2002). The synergistic action of the two solvents when used together, i.e., EDA, that cleaves the H-bonds, and NMP, that extracts aromatics, and leaves SCCs with negligible ash content. Fig. 4 summarizes the different compounds obtained from the OCs and SCCs. The highest amounts of mono-aromatics were obtained from the Bahula and Moonidih coals (both OC and SCC). NL OC gave predominantly mono-aromatics and alkenes, whereas NL SCC afforded relatively more n-alkanes and alkenes. The amounts of mono-, di- and tri-aromatics obtained during pyrolysis of the Bhagabandh SCC was relatively high as compared to the other coals (OCs and SCCs) indicating the effectiveness of the e,N solvent in extracting aromatics from this sample. Bhagabandh gave the highest extraction yield of all the coals. Based on these results, these coals and their SCCs could constitute a good source for the recovery of mono-aromatics such as benzene, toluene, xylene and other substituted aromatic compounds.

When the area \% of the five categories of the compounds were compared for their composition for a coking coal (Moonidih coal), and a non-coking high ash coal (Pandra coal), it was observed that the ash contents and the coking characteristics of coals effect the formation of certain coal macromolecules (Fig. 5(a) and (b)). The SCC (Fig. 5(b) obtained from the extraction of a coking coal Moonidih shows more monoaromatic content whereas that from the non-coking Pandra coal shows more alkenes. The tars of the SCCs obtained through the e,N solvent system show that the e,N extraction is largely aimed at the extraction of the specific moieties in coal, earlier studies have shown that the SCCs of the non-coking coals showed coking behavior extending their applicability in the steel industries (Pande 2000). Thus, the solvent extraction of the coals was found to enhance their coking properties by removing mono-aromatics and certain triaromatics, i.e., the use of mixed solvents may improve the coking properties of coal as well as significantly reducing the ash content.

\subsubsection{PCA Analysis}

PCA was carried out for the OCs and SCCs of the five coals to identify structural similarities and differences between the samples before and after solvent extraction. Additionally, through PCA analysis, it was possible to detect zones showing variability in the data and detect any outliers/abnormalities (Melendez et al. 2012). PCA was performed with coal samples as samples (rows) and compound groups/compounds as features/variables (columns). Principal Component 1 (PC1) with an eigen vector corresponding to the largest Eigen value of 354.35 captured $61.88 \%$ of variance in the data. Similarly, Principal Component 2 (PC2) with an Eigen vector corresponding to the second largest Eigen value of 120.31 captures $21.01 \%$ of variance in the data. Thus, the samples were represented on a 2D dimensional plane to visualize the spatial distribution relative to each other with axes PC1 and PC2 capturing total $82.89 \%$ of variation in the data, when total peak area corresponding to compounds grouped as in Fig. 4 , were considered as features. The loadings plot represents weight coefficient of each compound group, denoting the contribution of original features (dimensions) to the directions of principal axes of variation in data (Principal Components/Eigen Vectors).

In Fig. 6 (b), n-alkanes and n-alkenes make the major contribution to PC1 in the positive direction and the other compounds as a whole make significant contributions in the negative direction. Aromatic compounds have smaller weights as compared to alkanes, alkenes and other compounds, and they contribute to the negative side of PC1.Cycloalkanes lie close to the origin and have a small contribution in the positive PC1 direction. Aromatics have predominant contributions to PC2 with monoaromatic compounds having a high positive weight and diaromatics, triaromatics having negative weights. Alkenes and alkanes have smaller contributions in PC2 as compared to aromatics, with nearly equal weights but in opposite directions, i.e., positive and 
negative PC2 respectively.The original coals cluster together on the positive side of the PC1 axis, whereas, the super clean counterparts are spread on the negative side of PC1 with the exception of Neyveli Lignite SCC, which shows significant similarity to the original coals in the direction of maximum variance in the data.

After removing Neyveli lignite from the analysis, in the scores plot Fig. 7(a), the SCCs of Bahula, Moonidih, Bhagabandh and Pandra flip to the positive side of the PC1 in a pattern that is almost a mirror image about the PC2 axis. Since in the loadings plot, the n-alkanes, n-alkenes, monoaromatics and others have flipped to opposite sides too, the nature of the PC1 axis and its distinguishing characteristics based on the relative composition of samples is retained. The PC2 axis is still composed of a high positive weight of monoaromatics and negative weights of diaromatics and triaromatics. Diaromatics and triaromatics now have negligible loadings on PC1 and hence the specificity of PC2 increases and its nature is retained. Fig. 7 would be considered for further analysis.

PC1 distinguishes samples based on aliphatic and monoaromatics content whereas PC2 primarily differentiates samples based on aromatic content. Original coals have negative scores on PC1 and thus have high aliphatic content, comprising n-alkanes, nalkenes and cycloalkanes, as compared to solvent extracted super cleaned counterparts. For all samples, the major shift on PC1 as compared to a mild shift in PC2 scores supports the conclusions drawn by Sharma (Sharma et al. 2019). The general trend of decrease in Aliphatic/Aromatic content scores post e,N solvent extraction for both non-coking high ash and coking low ash coals. Intense aromatics bands in SCCs signifying increase in aromatics as pointed out in ATR FTIR analysis of samples, can be observed from the fact that monoaromatics have a positive loading on PC1 and coals' super cleaned samples having a higher negative PC2 score (shift towards more di- and triaromatics content) as compared to their original ones (Dhawan and Sharma 2019). This transformation was found to be more pronounced for non coking coals, i.e Bahula and Pandra Coals, for which average aromatic content increases as well as for all other aromatic groups, as reported by Sharma et al. (Sharma et al. 2019) . Significant increase in triaromatics content of Pandra Coal post solvent extraction is the highlight among this trend.

A total of 91 compounds can be identified through Py-GCMS of all samples together. The loadings and scores plot when PCA is done without clubbing compounds into groups, is presented in Fig. 8. Compounds having loadings more than 0.1 on either PC1 or PC2 have been labelled, as their loadings is considered significant. Original and super cleaned coals form clear distinct clusters on negative and positive halves of PC1, respectively. The all compound plots are found to be consistent with the analysis drawn from grouped compound plots, although specific deductions are difficult to make, given the large number of weights represented in loadings plot yet, in PC2 which comprises of significant loadings from both aromatics and aliphatic compounds, the distinguishing characteristics are not retained with both effects balancing each other making respective clean samples almost parallel to their raw ones. However, Bahula coals with significantly high content of phenols has been clearly highlighted. For low ash coking coal Moonidih, having highest content of polyaromatic structures, total aromatics content has been reported to be comparable before and after solvent extraction, whereas, distinct increase in other structural units like pyrrolidinones makes it super cleaned sample acquire high positive score on PC1.

\subsubsection{Gaussian Contour Plots}

As observed in Fig. 9, both contours are independent. The clusters are well separated and thus, the shape of mixture contours do not differ much from the component contours, given that the weights (number of sample points) are comparable. Both SCCs and OCs are positively correlated (ellipsoidal shape tilted to the right) and their PC1 and PC2 scores co-vary in the given 2D plane. Positive correlation implies that for both OCs and SCCs, as the positive score increases in the PC1 axis, the positive score in PC2 increases. Moonidih, Bhagabandh and Pandra OCs lie on the same contour curve and have the same probability density value. They belong to the original coals cluster under the same confidence limits.

\section{Conclusions}

Analytical pyrolysis results provide insights into the macromolecular structure of both coking and non-coking Indian original coals (OCs) and the selective action of the e,N solvent system, which produces products (SCCs) with improved coking properties and greatly reduced ash content. These coals could act as good sources for the production of monoaromatics such as benzene, toluene, phenol and substituted phenols, which have a wide array of industrial applications. Extensive Py-GCMS data analysis using PCA was performed on coal samples from five different Indian coal seams namely, Pandra, Bahula, Moonidih, Bhagabandh 
and Neyveli lignite and their corresponding SCCs. It primarily featured Scores and Loadings plots which expedited analysis of these samples based on relative composition of constituent compounds through an accurate but compact visualization. This analysis of samples' constituent compounds, initially, by categorizing on the basis of various hydrocarbon classes, and later, on the basis of individual compounds, was coherent and signified consistency of the mathematical formulation. The OCs and SCCs cluster on either sides of PC2 axis, except for NL-SCC, shows structural similarity to the OCs. Neyveli-Lignite has more volatile matter and moisture content and relatively lower ash content (5.2\%) compared to the other coal samples which may be attributed to its varied behaviour from the other cluster of samples. Cluster characteristics and contour orientation were determined using GMM algorithm. ATR-FTIR supported the inferences drawn from the Py-GCMS and PCA studies, showing enhanced intensity of the aromatic bands in the SCCs as compared to OCs. Analysis of the ATR-FTIR spectra further led to the conclusion that the SCCs behave similarly for both coking and non-coking coals, verifying the selective action of the e,N solvent system on the polycondensed aromatic structures in the coals. Moonidih coal and its SCC was found to have the highest total content of aromatics.

\section{Declarations}

\section{Competing interests}

The authors declare no conflicts of interest.

\section{Funding}

Grant No. TMD/CERI/MDME/2017/001(G) from the Department of Science and Technology, New Delhi, India.

\section{Author Contributions}

Abyansh: Visualization, Data analysis; Writing- Original draft preparation; Heena: Experimental Investigation, Data curation; Kondamana: Conceptualization; Supervision, Reviewing; Sreedevi Upadhyayula: Conceptualization, Methodology, Supervision, Reviewing and Editing

\section{Acknowledgments}

The authors Sreedevi Upadhyayula acknowledges funding (Grant No. TMD/CERI/MDME/2017/001(G)) from the Department of Science and Technology, New Delhi, India. Dr. Heena Dhawan is thankful to Prof. D.K. Sharma, Retired Professor of Centre for Energy Studies, IIT Delhi for his help with the coal samples and continuous guidance through the work and Prof. M. Crocker and T. Morgan, Center for Applied Energy Research, University of Kentucky, Lexington, KY 40511, USA for the Py-GCMS analysis.

\section{References}

1. Balachandran M (2014) Role of infrared spectroscopy in coal analysis-an investigation. Am J Anal Chem 5; 367-372.

2. Cooke NE, Fuller OM, Gaikwad RP (1986) FT-ir spectroscopic analysis of coals and coal extracts. Fuel 65:1254-1260

3. De Lira L de FB, De Vasconcelos FVC, Pereira CF, et al (2010) Prediction of properties of diesel/biodiesel blends by infrared spectroscopy and multivariate calibration. Fuel 89:405-409

4. Dhawan H, Sharma DK (2019) Refining of Indian coals to obtain super clean coals having insignificant amounts of deleterious elements under milder conditions. Miner Process Extr Metall 1-12

5. Fardhyanti DS (2015) Analysis of Coal Tar Compositions Produced from Sub-Bituminous Kalimantan Coal Tar. Int J Chem Mol Eng 9:1022-1025

6. Friesen WI, Ogunsola OI (1994) Principal component analysis of upgraded Western Canadian coals. Fuel Process Technol 38:139-151

7. Fujitsuka H, Ashida R, Miura K (2013) Upgrading and dewatering of low rank coals through solvent treatment at around $350 \mathrm{C}$ and low temperature oxygen reactivity of the treated coals. Fuel 114:16-20 
8. Harman-Ware AE, Crocker M, Pace RB, et al (2015) Characterization of endocarp biomass and extracted lignin using pyrolysis and spectroscopic methods. BioEnergy Res 8:350-368

9. Huber GW, Iborra S, Corma A (2006) Synthesis of transportation fuels from biomass: chemistry, catalysts, and engineering. Chem Rev 106:4044-4098

10. Islas CA, Suelves I, Carter JF, et al (2000) Pyrolysis-gas chromatography/mass spectrometry of a coal extract and its fractions separated by planar chromatography: correlation of structural features with molecular mass. Rapid Commun Mass Spectrom 14:1766-1782

11. Makan SR, Alexander JA, Solomon RA, et al (2017) Physicochemical Characterization of Coal Tar Produced by Pyrolysis of Coal from Garin Maiganga and Shankodi Deposits. J Miner Mater Charact Eng 5:288-297

12. Masayuki S, Masanori Y, Kensuke K, Kiyotaka T (2011) Reduction of GHG emissions by ash free coal utilization. Int J Sustain Energy Inst 1:22-30

13. Meier D, Fortmann I, Odermatt J, Faix O (2005) Discrimination of genetically modified poplar clones by analytical pyrolysisgas chromatography and principal component analysis. J Anal Appl Pyrolysis 74:129-137

14. Melendez L V, Lache A, Orrego-Ruiz JA, et al (2012) Prediction of the SARA analysis of Colombian crude oils using ATR-FTIR spectroscopy and chemometric methods. J Pet Sci Eng 90:56-60

15. Molina D, Uribe UN, Murgich J (2010) Correlations between SARA fractions and physicochemical properties with $1 \mathrm{H}$ NMR spectra of vacuum residues from Colombian crude oils. Fuel 89:185-192

16. Mullins OC (2010) The modified Yen model. Energy \& Fuels 24:2179-2207

17. Niedoba T (2014) Multi-parameter data visualization by means of principal component analysis (PCA) in qualitative evaluation of various coal types. Physicochem Probl Miner Process 50:

18. Odeh AO (2015) Oualitative and quantitative ATR-FTIR analysis and its application to coal char of different ranks. J Fuel Chem Technol 43:129-137

19. Okuyama N, Komatsu N, Shigehisa T, et al (2004) Hyper-coal process to produce the ash-free coal. Fuel Process Technol 85:947-967

20. Pande S (2000) Studies on Ethylenediamine assisted N-Methyl-2pyrrolidone extraction of coal scale up of the procen and utilization of the super clean coal obtained

21. Pande S, Sharma DK (2001) Studies of kinetics of diffusion of N-methyl-2-pyrrolidone (NMP), ethylenediamine (EDA), and $\mathrm{NMP}+\mathrm{EDA}(1: 1, \mathrm{vol} / \mathrm{vol})$ mixed solvent system in Chinakuri coal by solvent swelling techniques. Energy \& fuels 15:10631068

22. Pande S, Sharma DK (2002) Ethylenediamine-assisted solvent extraction of coal in N-methyl-2-pyrrolidone: synergistic effect of ethylenediamine on extraction of coal in N-methyl-2-pyrrolidone. Energy \& fuels 16:194-204

23. Pattiya A, Titiloye JO, Bridgwater A V (2010) Evaluation of catalytic pyrolysis of cassava rhizome by principal component analysis. Fuel 89:244-253

24. Rađenović A (2006) Pyrolysis of coal. Kem u Ind Časopis kemičara i Kem inženjera Hrvat 55:311-320

25. Schwarzinger $C$ (2005) Identification of fungi with analytical pyrolysis and thermally assisted hydrolysis and methylation. $J$ Anal Appl Pyrolysis 74:26-32

26. Sharma DK, Dhawan H (2018) Separative refining of coals through solvolytic extraction under milder conditions: A review. Ind Eng Chem Res 57:8361-8380

27. Sharma DK, Dhawan H, Morgan T, Crocker M (2019) Py-GCMS studies of Indian coals and their solvent extracted products. Fuel 256:115981

28. Sun M, Ma X-X, Yao Q-X, et al (2011) GC-MS and TG-FTIR study of petroleum ether extract and residue from low temperature coal tar. Energy \& Fuels 25:1140-1145

29. Tesch S, Otto M (1995) Application of principal-component analysis to the interpretation of brown coal properties. Fuel 74:978-982

30. Van Krevelen DW (1993) Coal: typology, physics, chemistry, constitution. Elsevier Amsterdam 
31. Yan J, Bai Z, Bai J, et al (2014) Effects of organic solvent treatment on the chemical structure and pyrolysis reactivity of brown coal. Fuel 128:39-45

32. Zhang D, Liu P, Lu X, et al (2016) Upgrading of low rank coal by hydrothermal treatment: Coal tar yield during pyrolysis. Fuel Process Technol 141:117-122

\section{Figures}

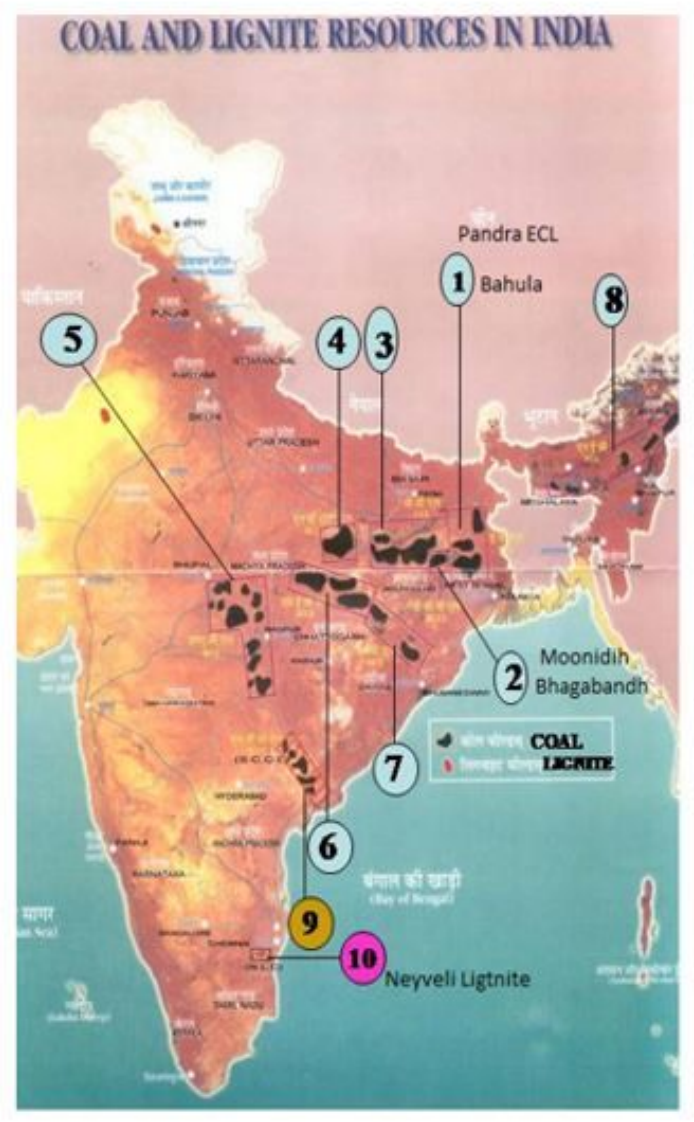

\section{MAJOR COAL PRODUCING} COMPANIES

A) COALINDIALTD. RASTERN COALFIELIDS LTD. (1) BHARAT COKING COAL LTD. (2) CENTRAL COALIKIELLS ITTD. (3) NORTHERN COALFIELDS LTD. (4) WESTERN COALIFIELDS LTD. (5) SOUTH FASTERN COALFIELDS LTD. (6) MAHANADI COALFIEL.DS LTD. (7) NORTH FASTERN COALFIEI,DS. (8) (A UNIT UNDER CIL(HO) ) CENTRAL MINE PLANNIING \& DISIGN INSTTIUTE

IB) SIINGARRENI COLIIIEIRIES CO. LiTII).

C) NIEYVELIILIGNITE CORIPORATION

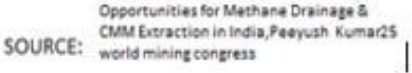

Figure 1

Location of Coal Samples illustrated on Map of India 


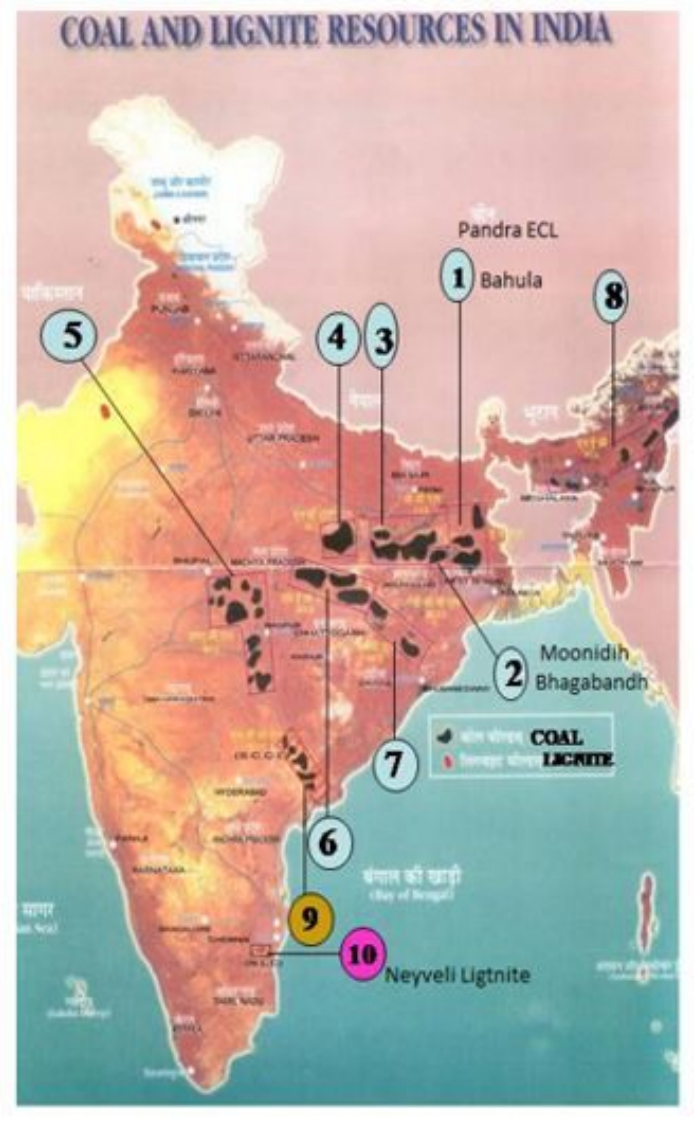

\section{MAJOR COAL PRODUCING} COMPANIES
A) COALINDIALTD. FASTTRR COALFTEILS LTD. (1) BHARAT COKING COAL LTD. CENTRAL COAIJIIELIDS HTD. (3) NORTHERN COALFIELDS LTD. WESTERN COALFTELDS LTD. SOUTH EASTERN COALFIELLS LTD. (6) MAHANADI COALFIELDS LTD. (7) NORTH FASTERN COALIFIEILDS. (8) (A UNIT UNDER CIL(HO) ) CENTRAL MINE PLANNINC \& DISIGN INSTTrUTE

BB) SINGARENI COLLIILIRIILSCO. I'TII).

C) NEYVIELILIGNITLE CORIPORATION

Figure 1

Location of Coal Samples illustrated on Map of India 


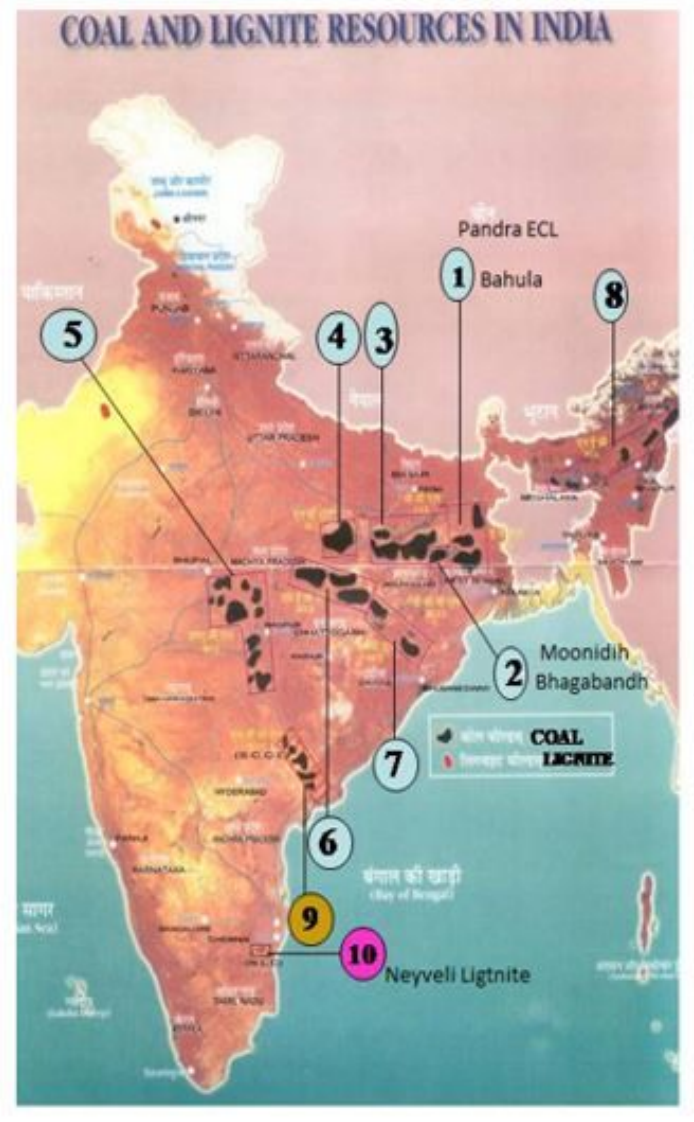

\section{MAJOR COAL PRODUCING} COMPANIES

A) CoAl indialtid. RASTERN COALWTELIDS LTD. (1) BHARAT COKING COAL ITT. (2) CENTRAL COALIFIELLS LTTD. (3) NORTHIERN COALFIELDS LTD. (4) WESTERN COALFIELDS LTD. (5) SOUTH EASTERN COALFTELDS LTD. (6) MAHANADI COALFIELDS LTD. (7) NORTH RASTERN COALWIELIDS. (8) (A UNIT UNDER CIL(HO) ) CENTRAL MINE PLANNINC \& DESIGN INSTTIUTE

IB) SINGAURENI COLIIIEIRILS CO. I'TII).

C) NIEYVIELILIGNITTE CORIPORATION

Figure 1

Location of Coal Samples illustrated on Map of India 


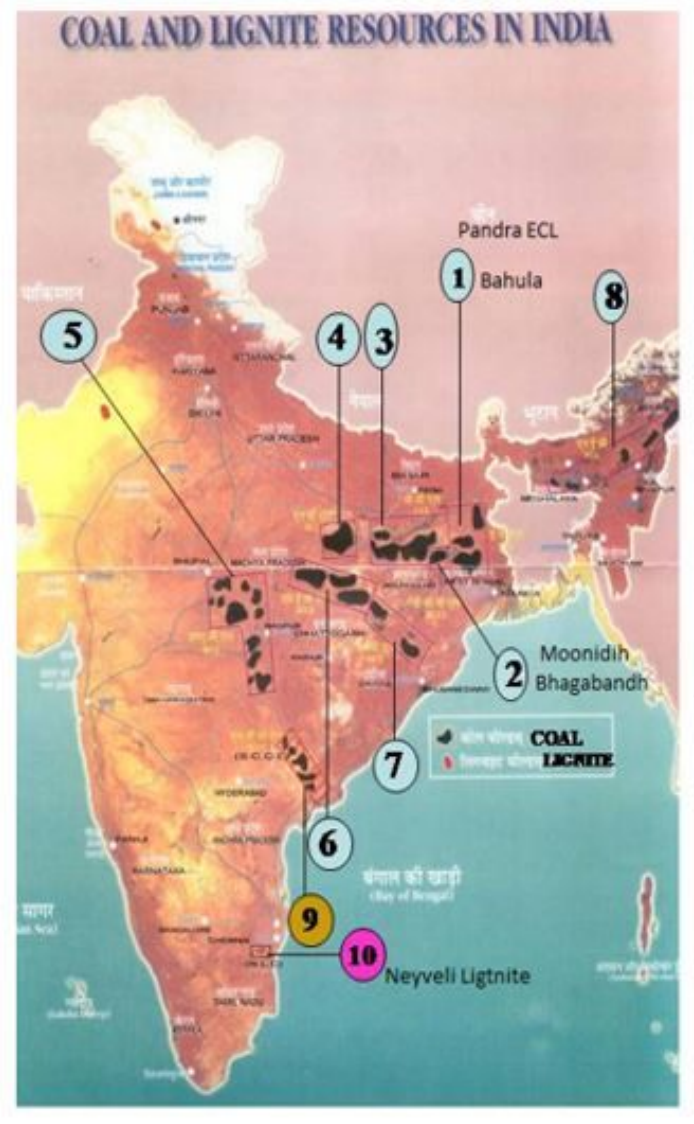

\section{MAJOR COAL PRODUCING COMPANIES}

A) COALINDIALTD. EASTERN COALFIELDS LTD. BHARAT COKING COAL LTD. (2) CENTRAL COALJFIELIDS HTD. (3) NORTHERN COALFIELDS LTD. (4) WESTERN COALFIELDS LTD. SOUTH EASTERN COALFTELDS LTD. (6) MAHANADI COALFIELDS LTD. (7) NORTH IASTERN COALIFIELDS. (8) (A UNIT UNDER CIL(HO) ) CENTRAL MINIE PLANNINC \& DISIGN INSTTIUTE

BB) SINGARRINI COLIIILIRULSCO. L'TII).

\section{C) NEYVIELILIGNITLE} CORTORATITON (10)

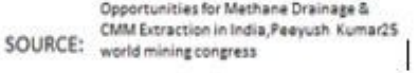

Figure 2

Location of Coal Samples illustrated on Map of India
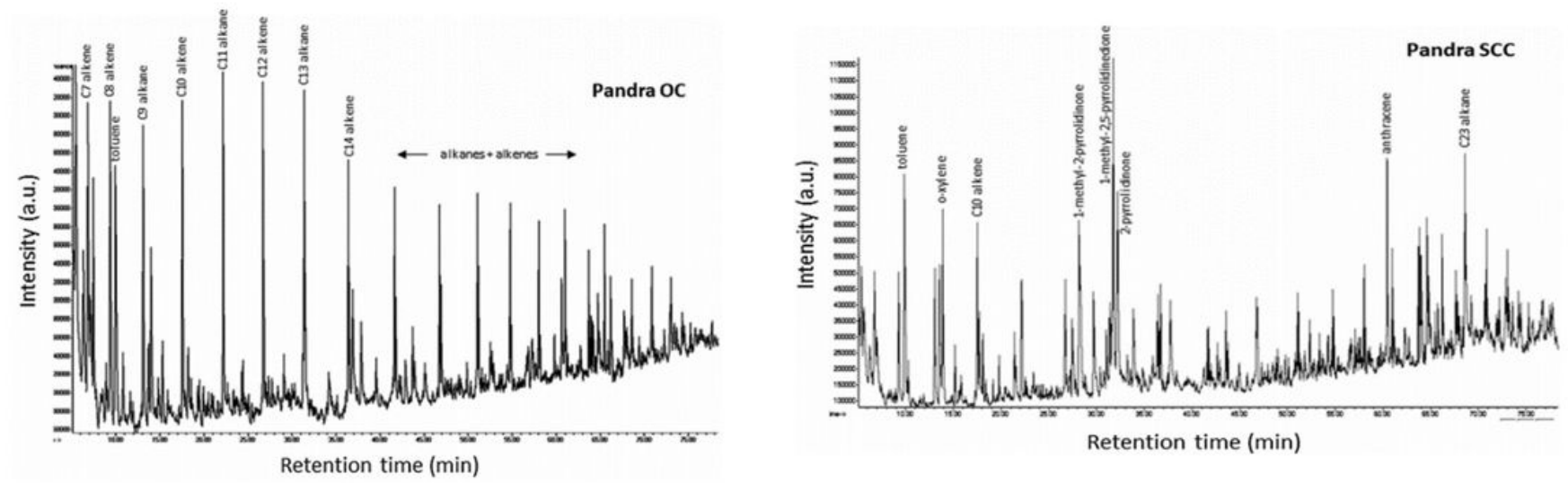

Figure 3

Pyrograms of Pandra (a) OC and (b) SCC (Sharma et al. 2019) 

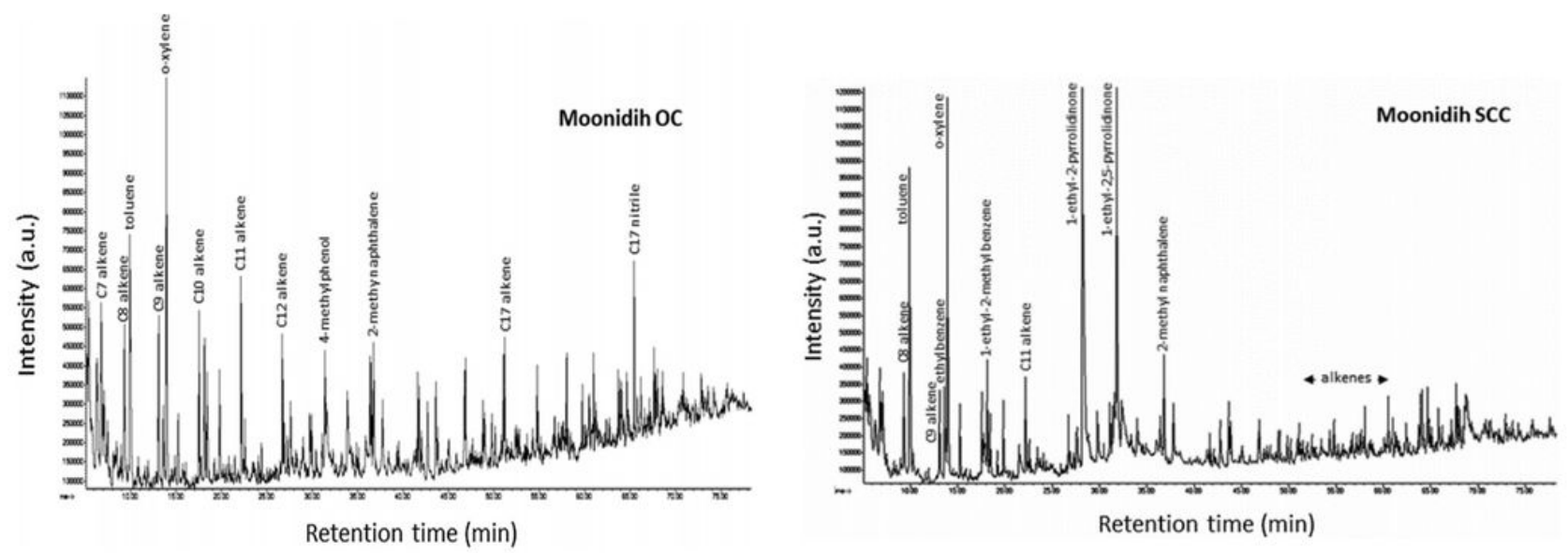

Figure 3

Pyrograms of Moonidih (a) OC and (b) SCC (Sharma et al. 2019)
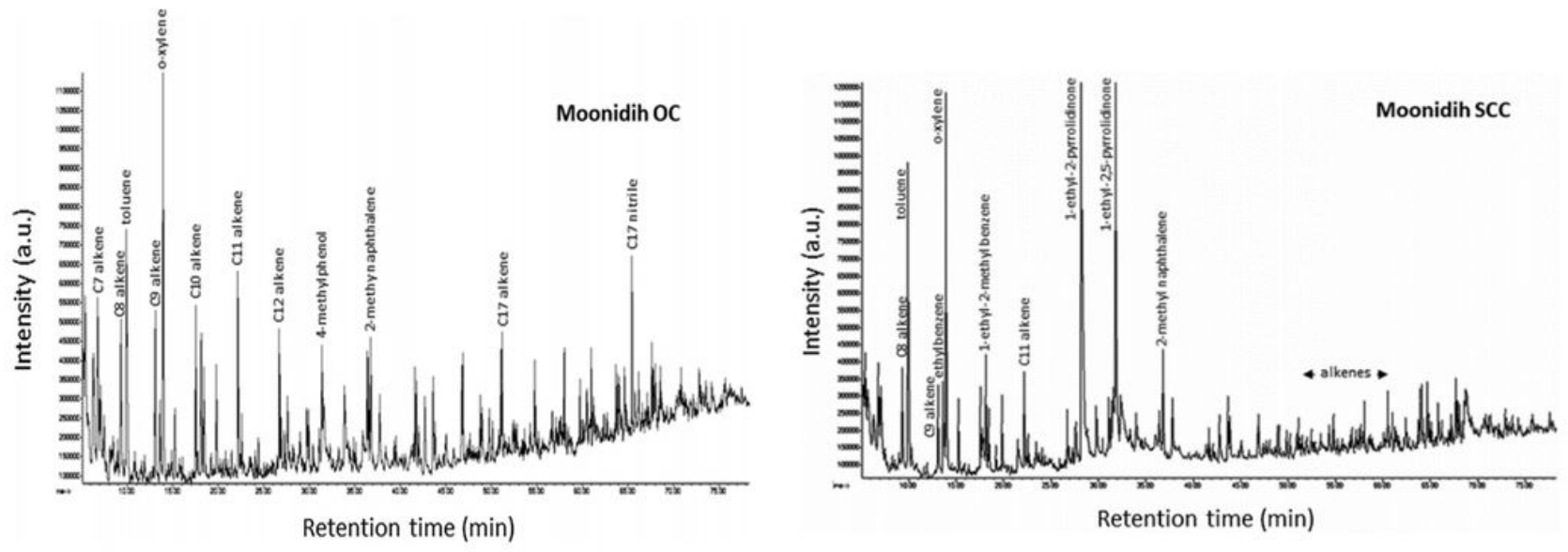

Figure 3

Pyrograms of Moonidih (a) OC and (b) SCC (Sharma et al. 2019) 

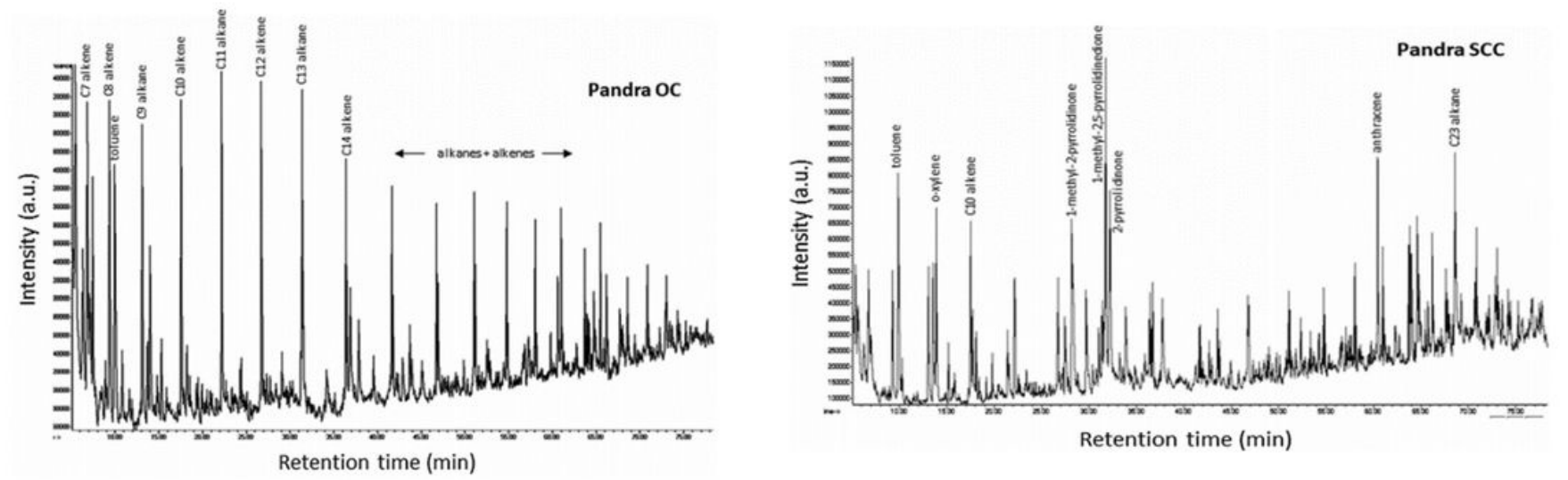

Figure 3

Pyrograms of Pandra (a) OC and (b) SCC (Sharma et al. 2019)

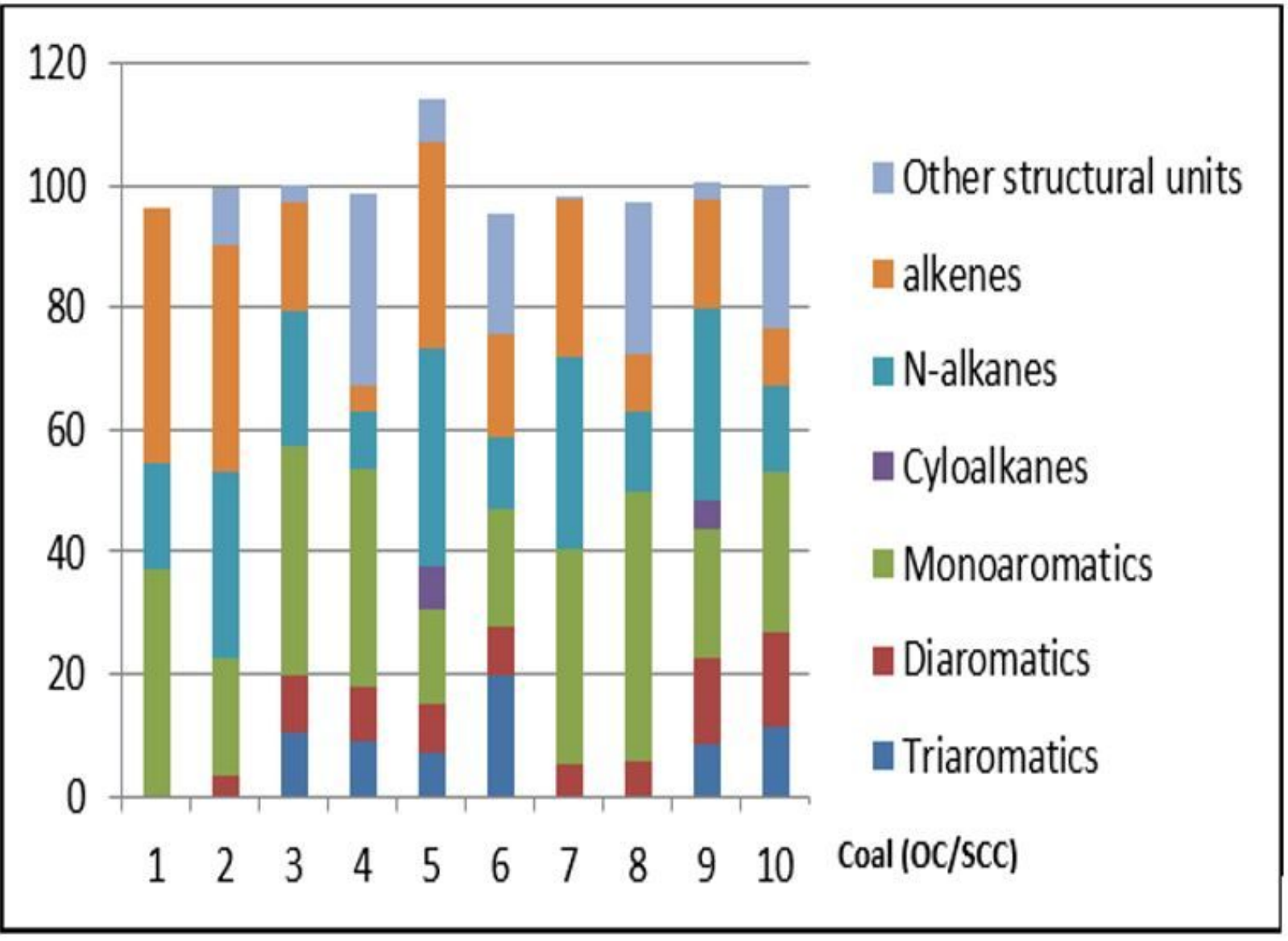

Figure 4

Area (\%) of the different compounds (y axis) 

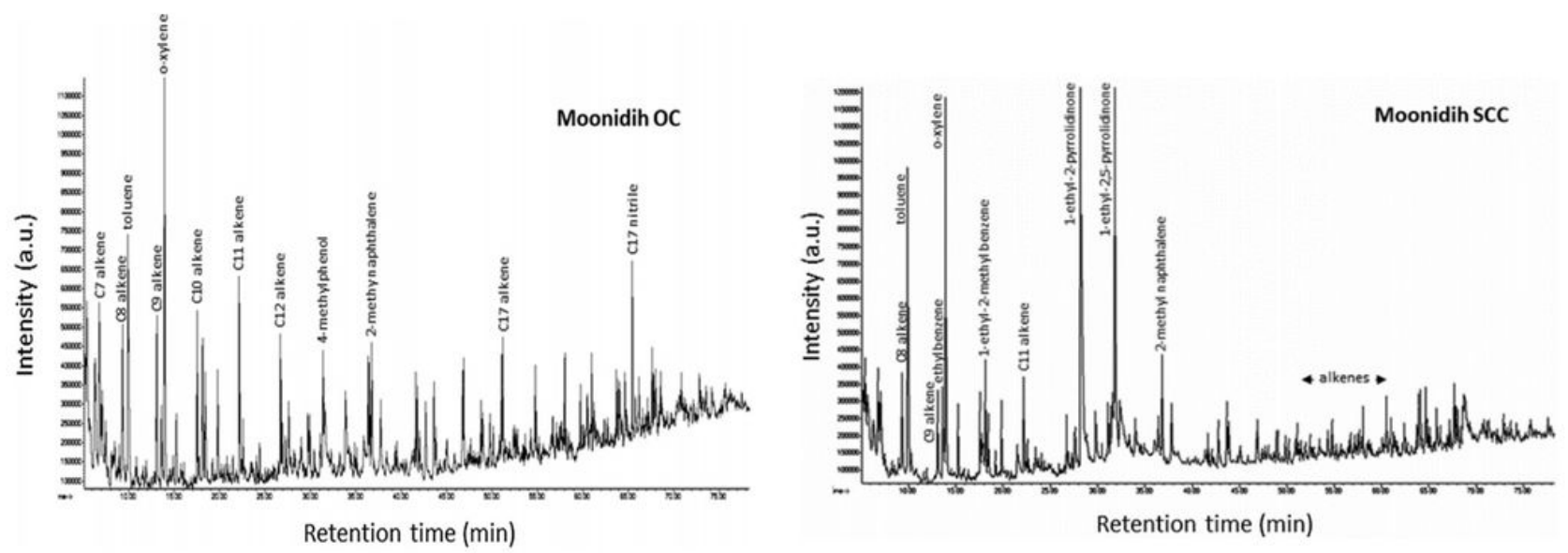

Figure 4

Pyrograms of Moonidih (a) OC and (b) SCC (Sharma et al. 2019)

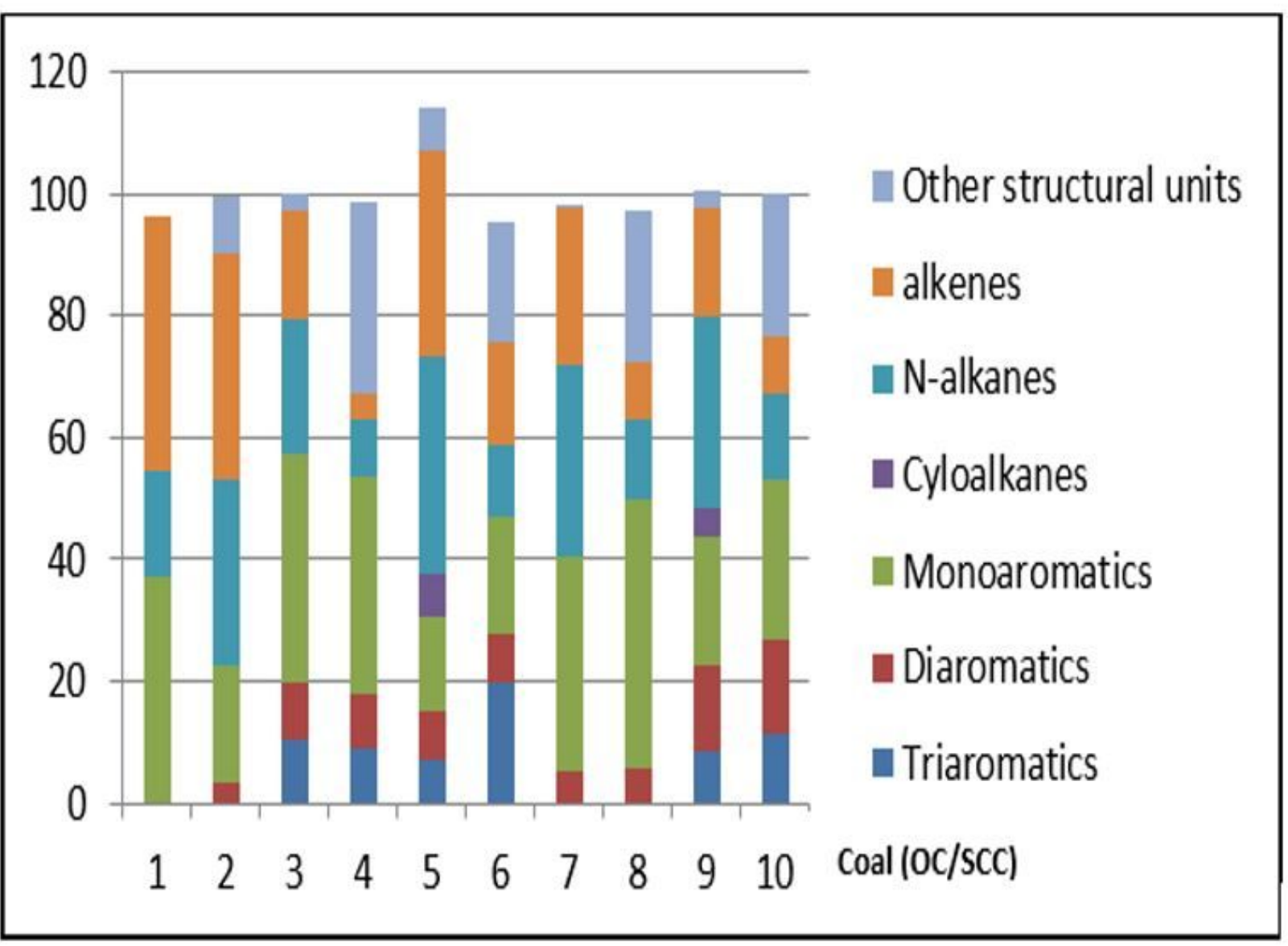

Figure 4

Area (\%) of the different compounds (y axis) 


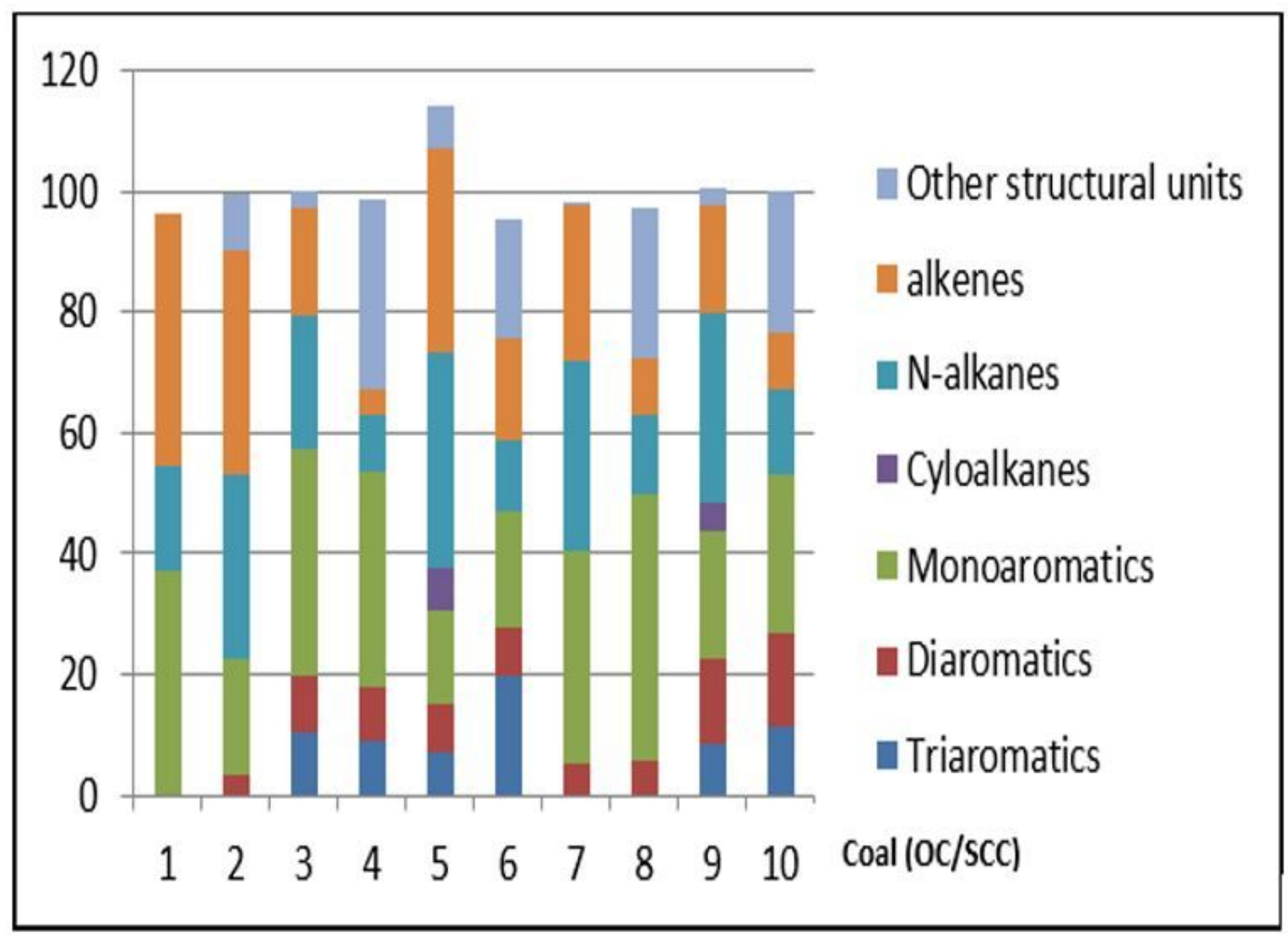

Figure 5

Area (\%) of the different compounds (y axis)

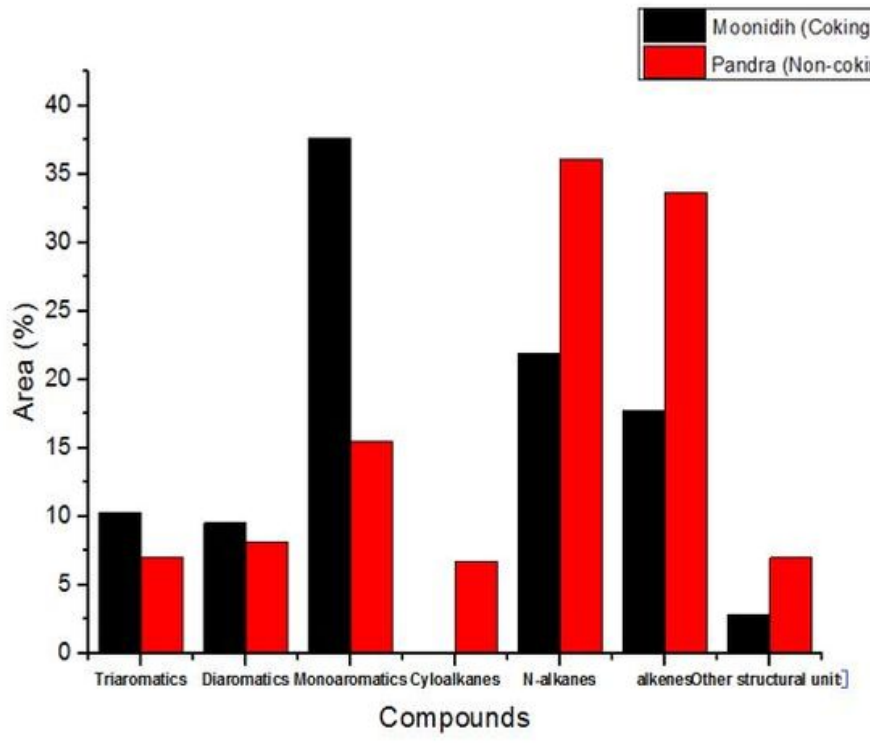

(a)

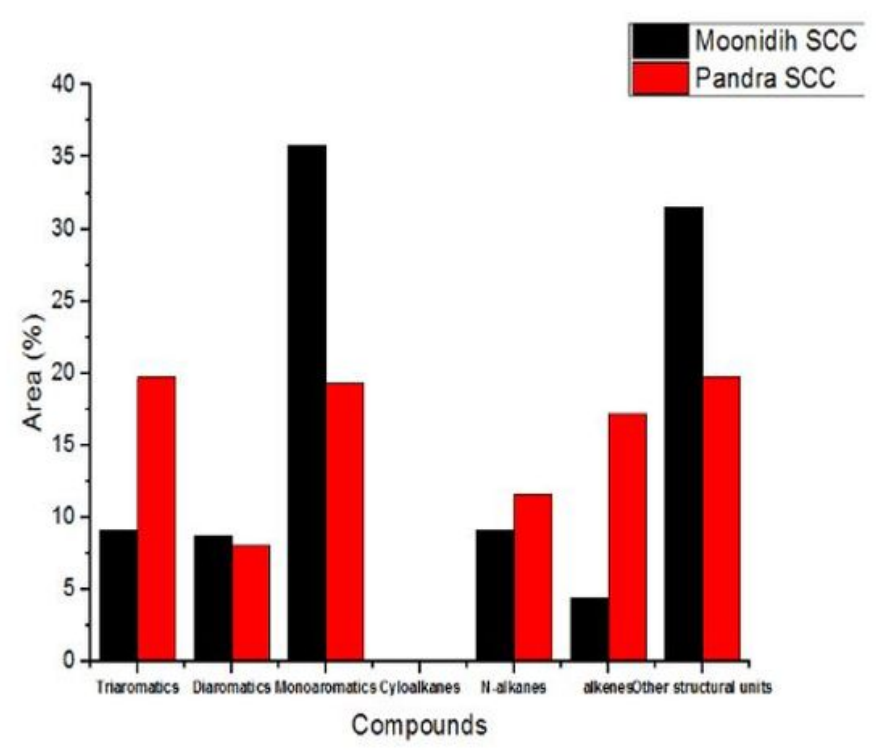

(b)

Figure 5

Pyrolysis product comparison for (a) coking and non-coking OC (b) coking and non-coking SCC 


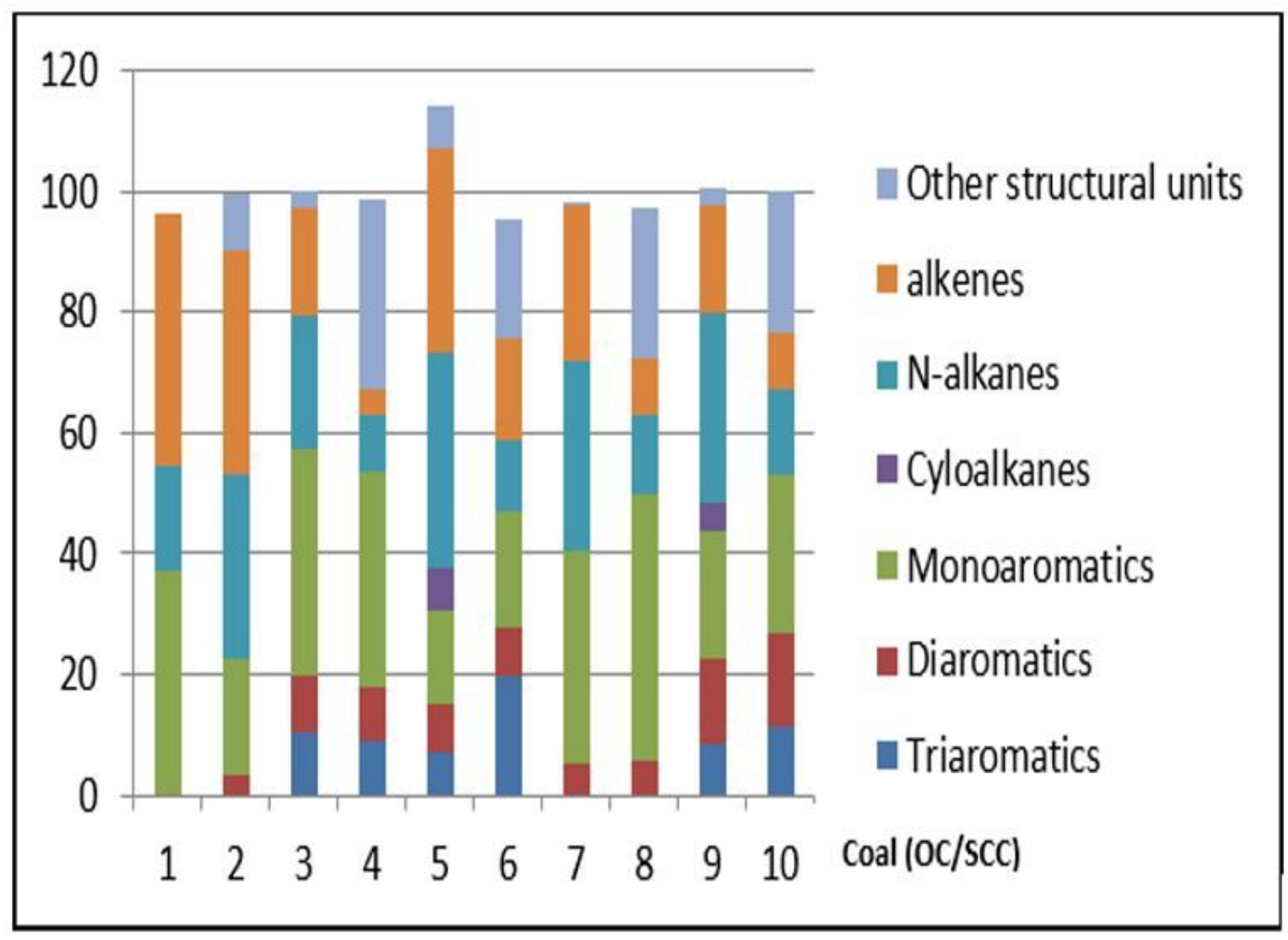

Figure 5

Area (\%) of the different compounds (y axis)

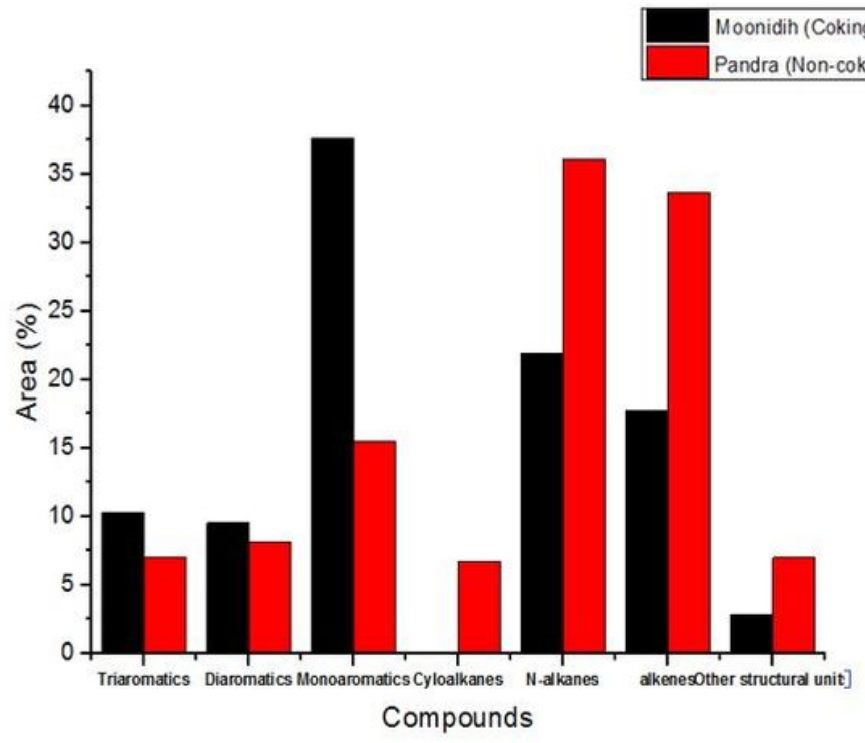

(a)

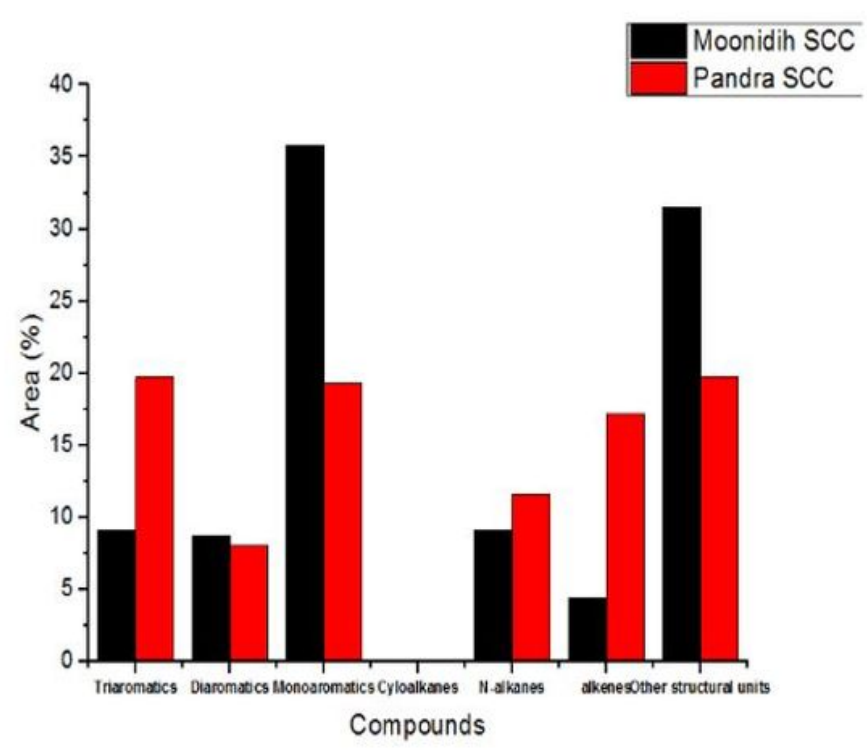

(b)

Figure 5

Pyrolysis product comparison for (a) coking and non-coking OC (b) coking and non-coking SCC 


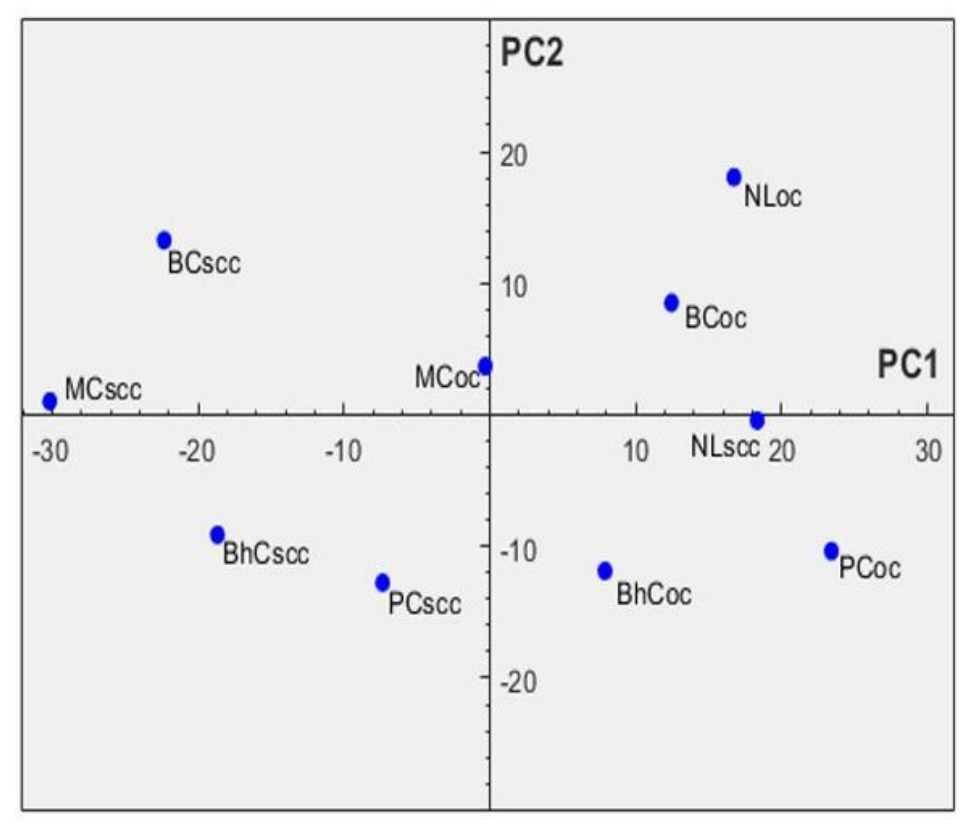

(a)

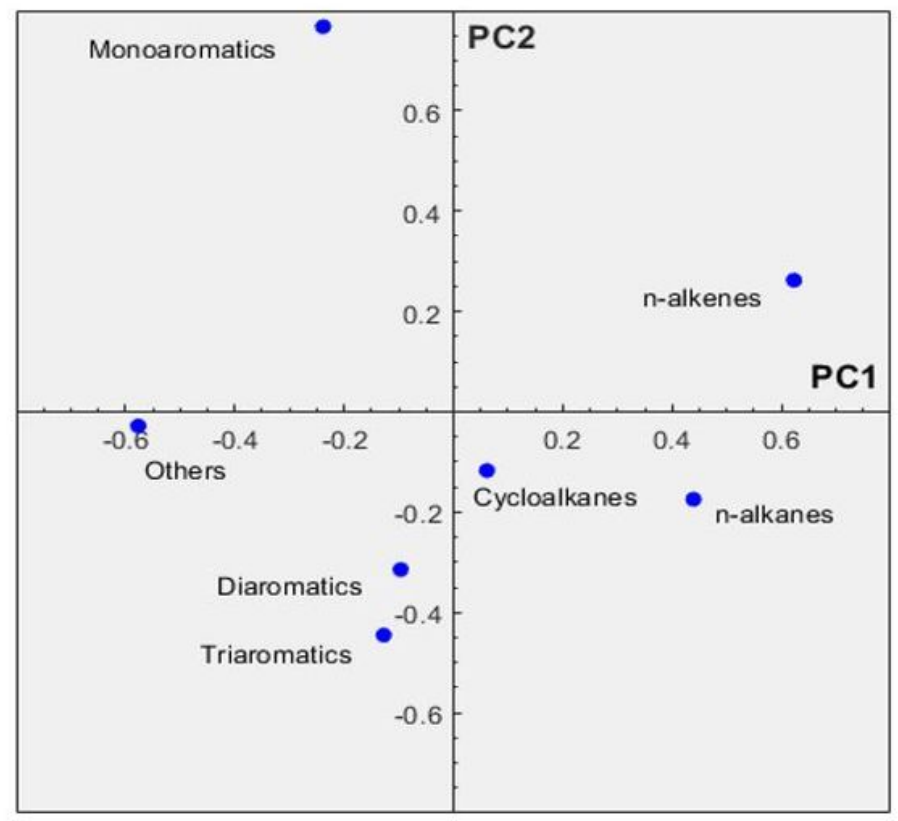

(b)

\section{Figure 6}

Principal Component Scores Plot (a) and Loadings Plot (b) for Indian coals (OCs and SCCs)

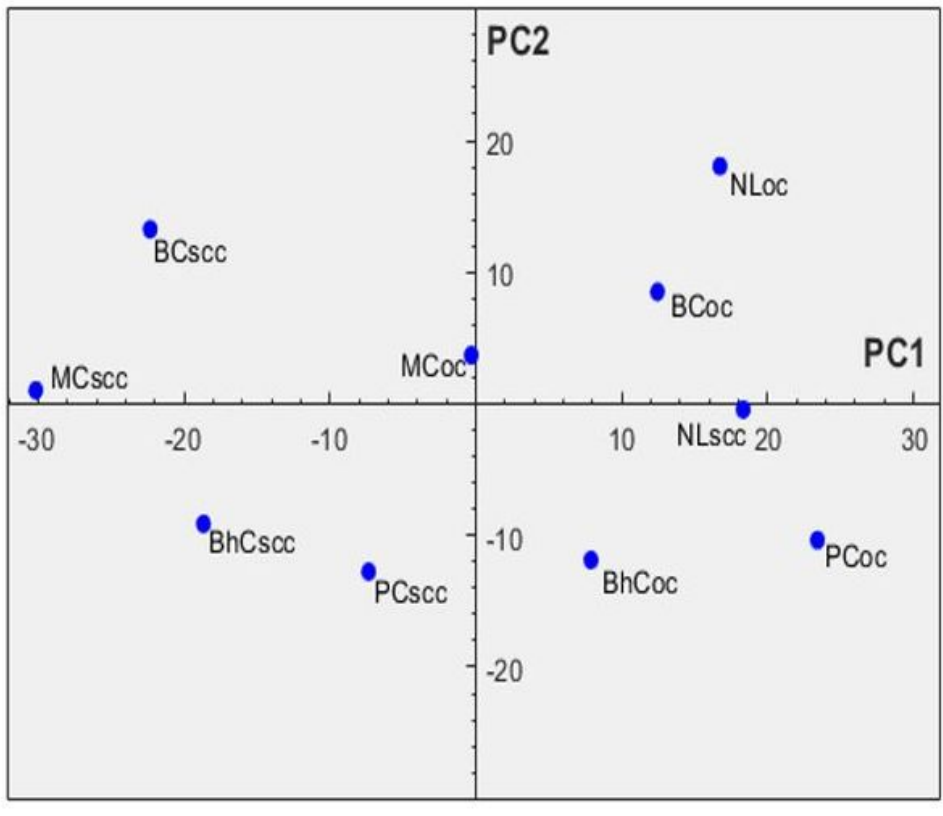

(a)

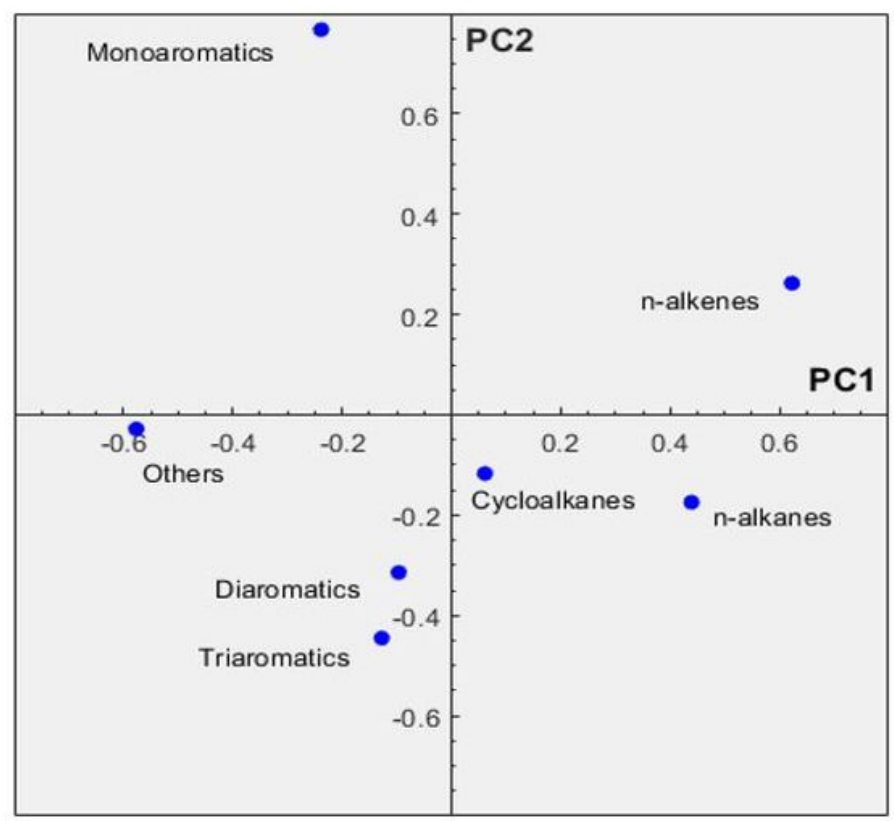

(b)

\section{Figure 6}

Principal Component Scores Plot (a) and Loadings Plot (b) for Indian coals (OCs and SCCs) 


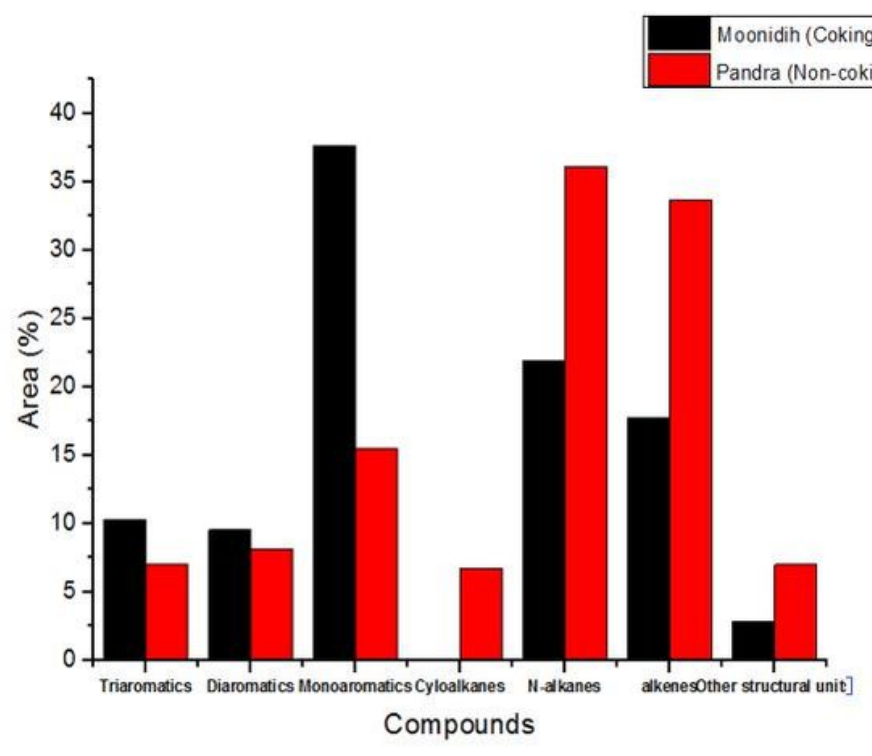

(a)

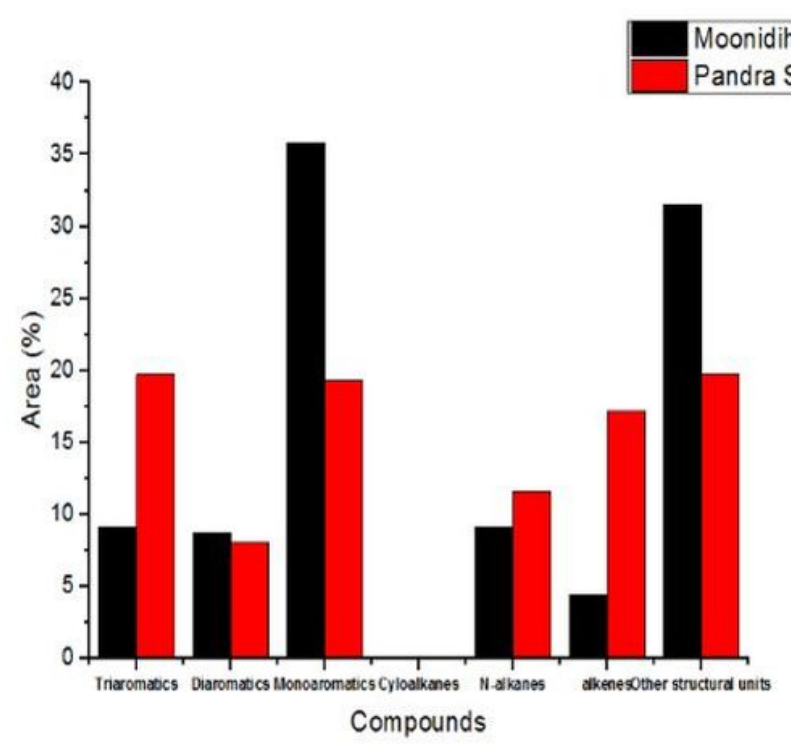

(b)

\section{Figure 6}

Pyrolysis product comparison for (a) coking and non-coking OC (b) coking and non-coking SCC

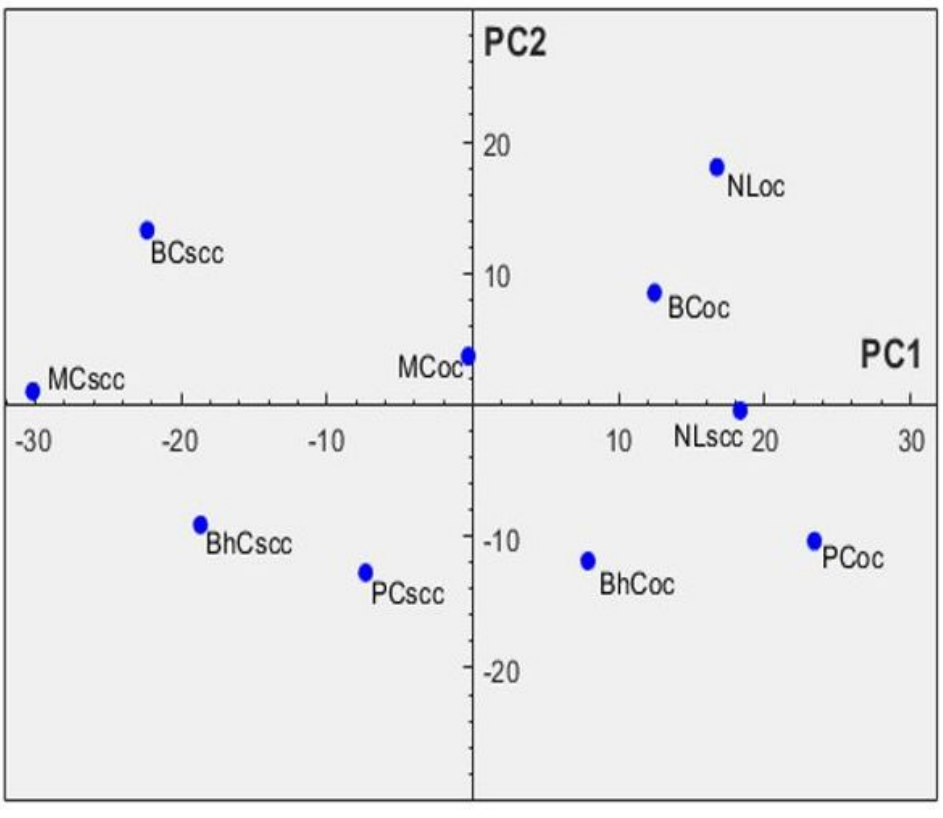

(a)

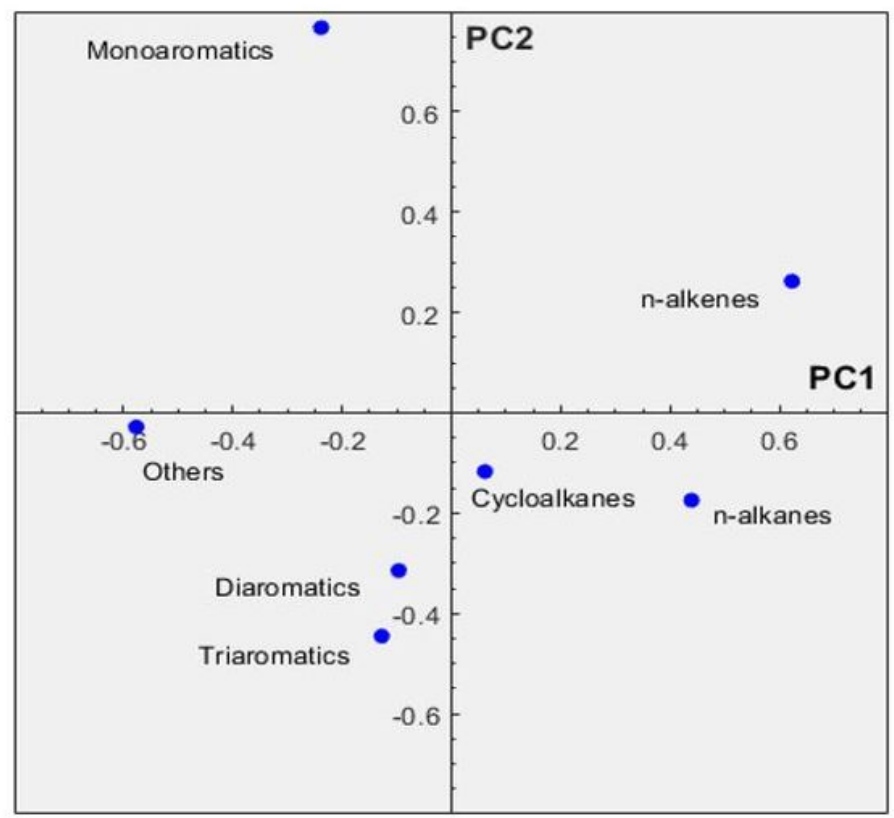

(b)

\section{Figure 6}

Principal Component Scores Plot (a) and Loadings Plot (b) for Indian coals (OCs and SCCs) 


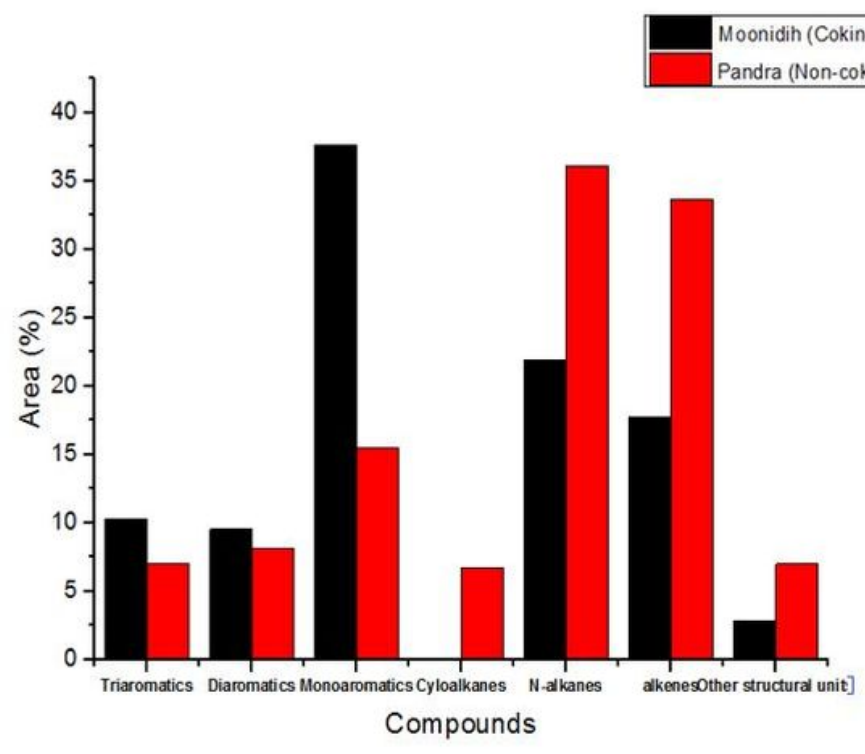

(a)

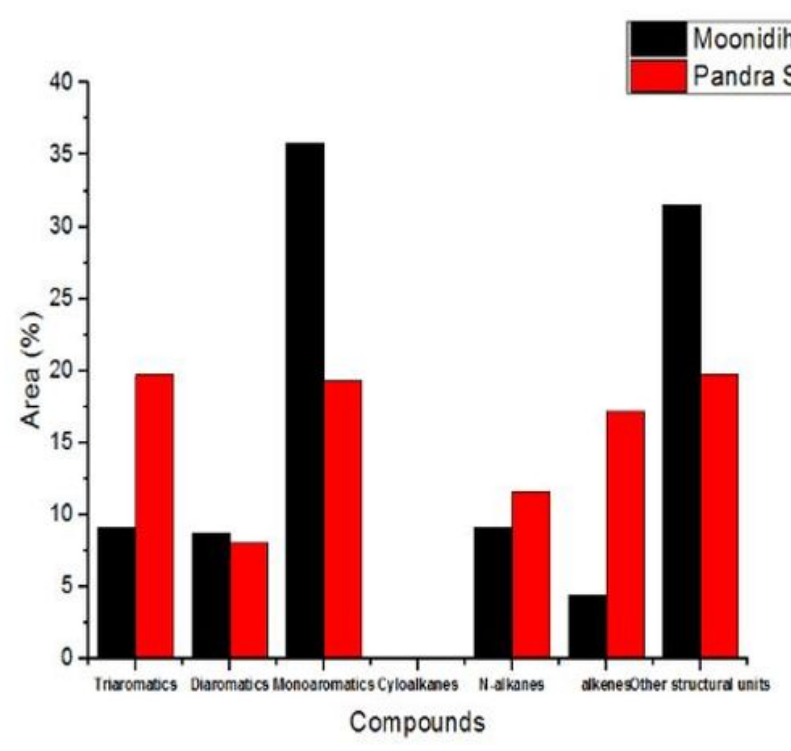

(b)

\section{Figure 6}

Pyrolysis product comparison for (a) coking and non-coking OC (b) coking and non-coking SCC

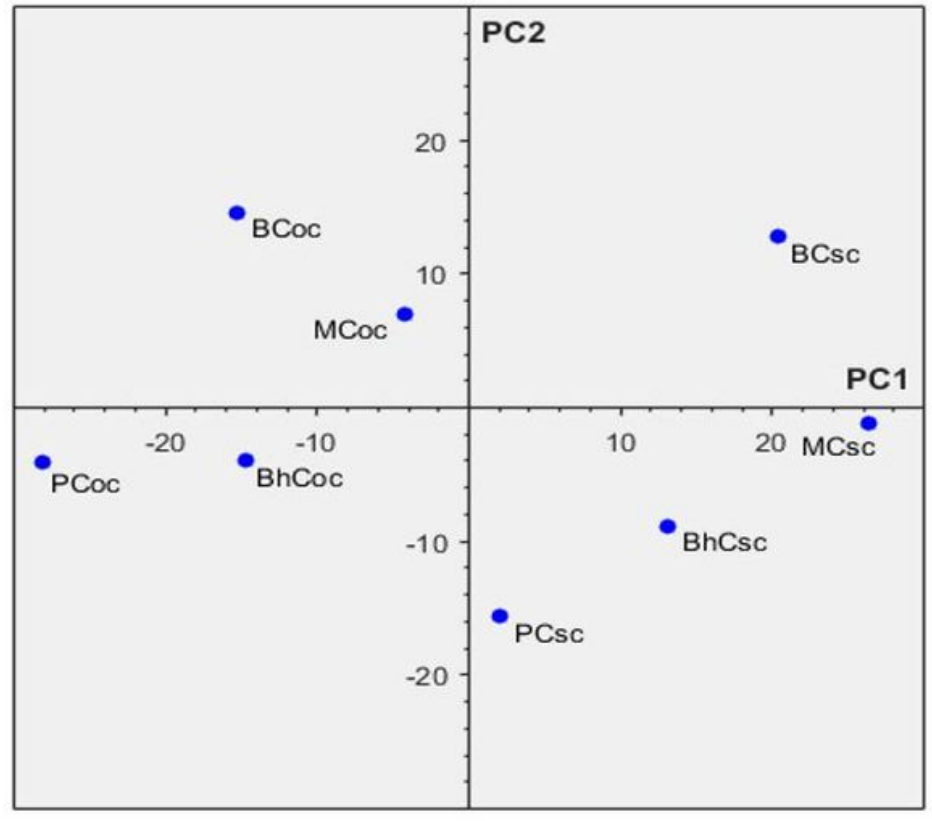

(a)

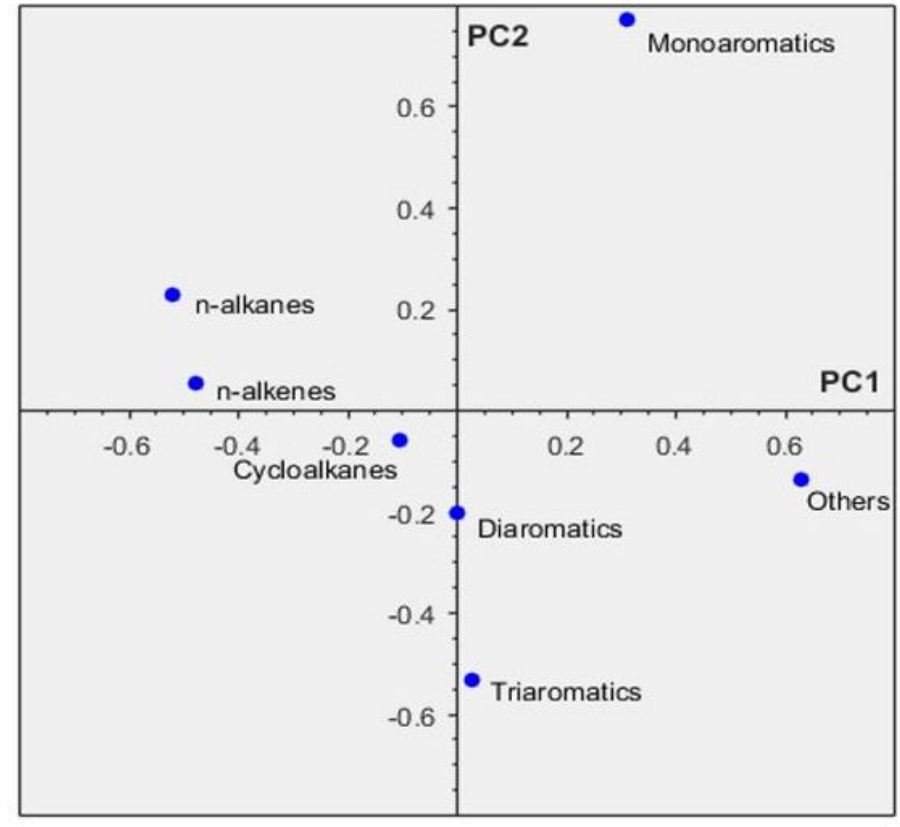

(b)

\section{Figure 7}

Scores Plot (a) and Loadings Plot (b) excluding the Neyveli Lignite 


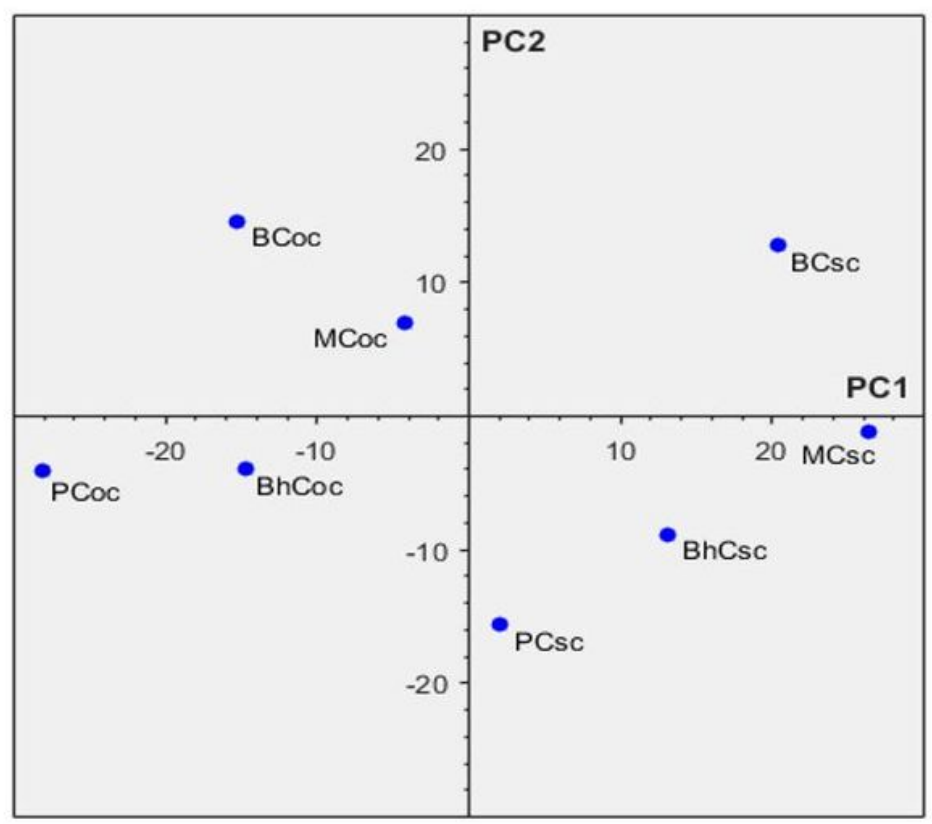

(a)

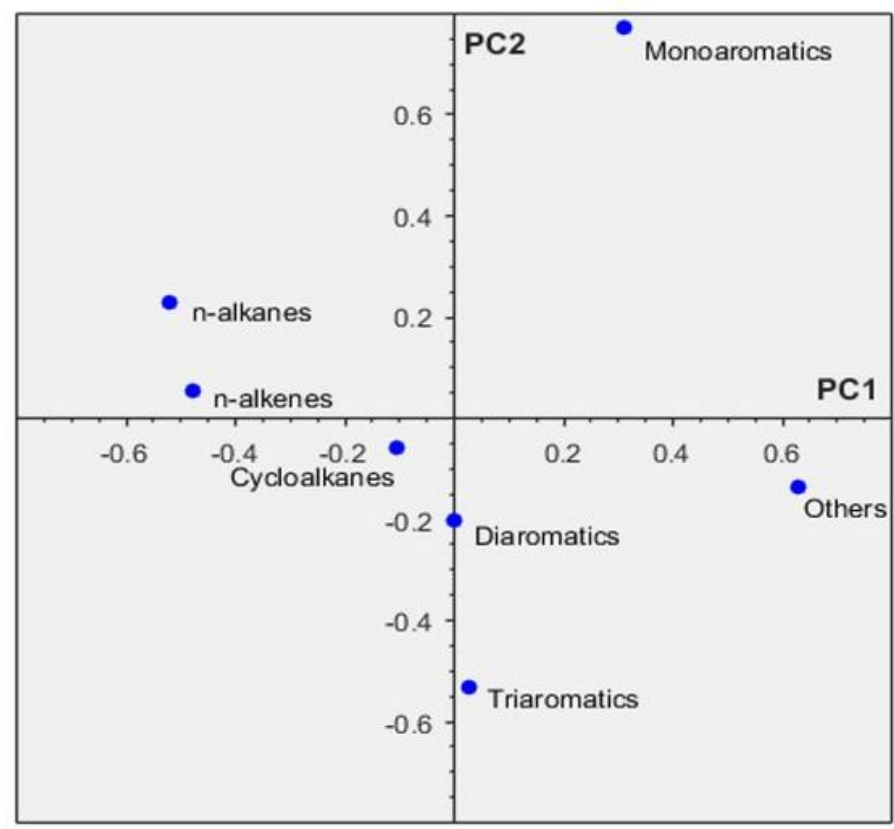

(b)

Figure 7

Scores Plot (a) and Loadings Plot (b) excluding the Neyveli Lignite

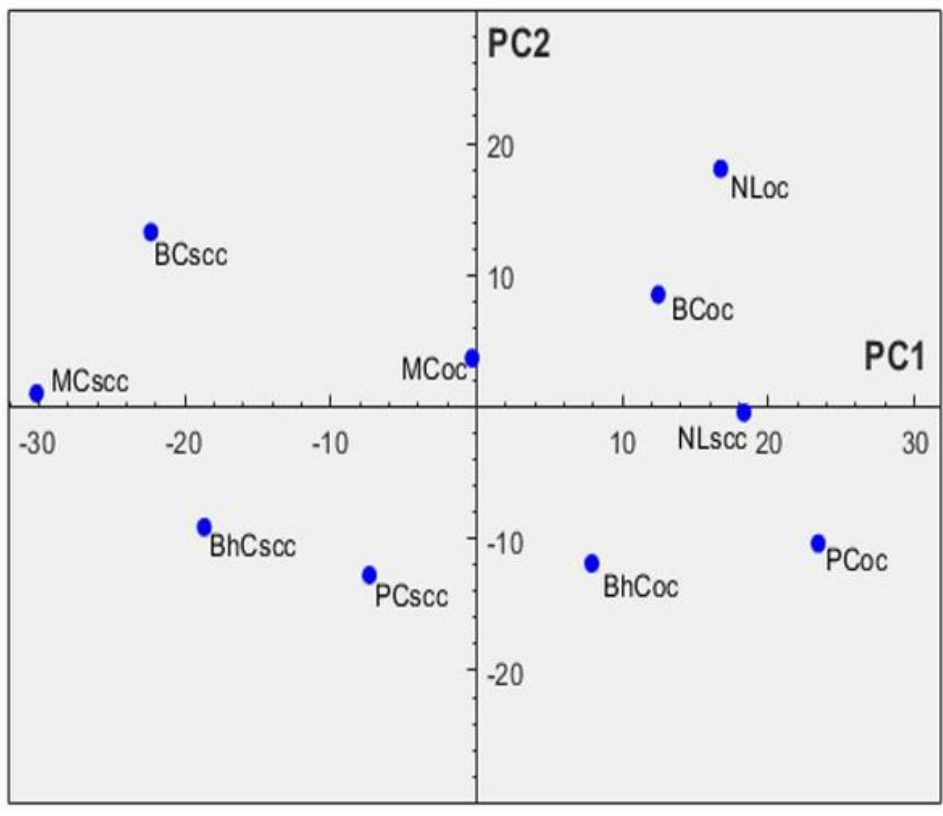

(a)

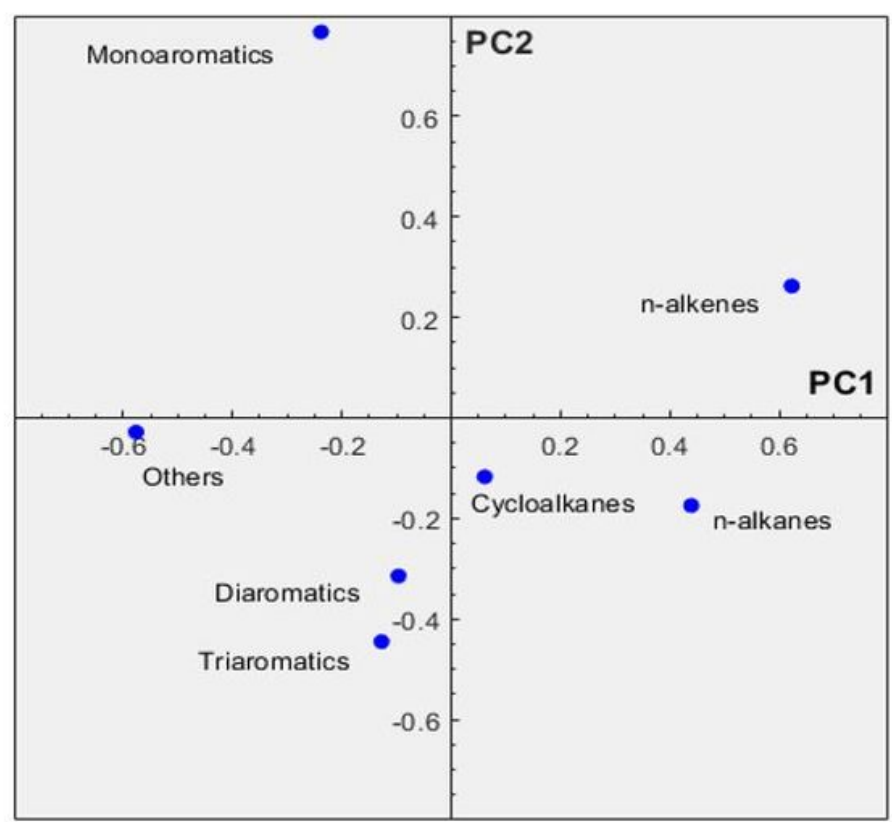

(b)

Figure 7

Principal Component Scores Plot (a) and Loadings Plot (b) for Indian coals (OCs and SCCs) 


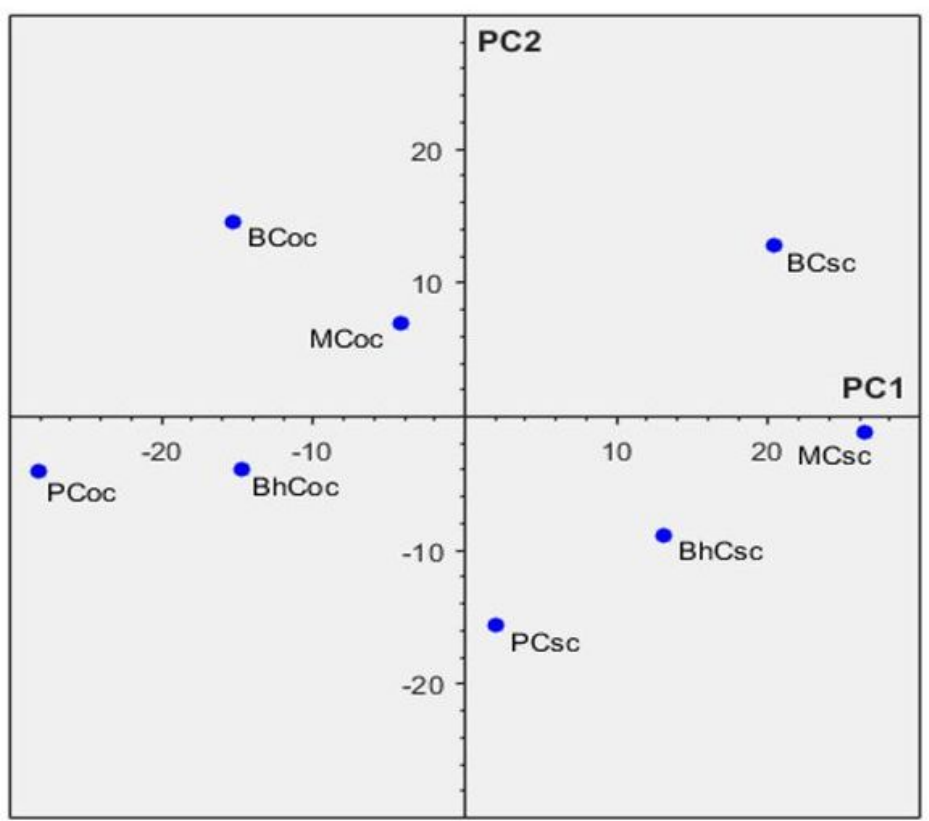

(a)

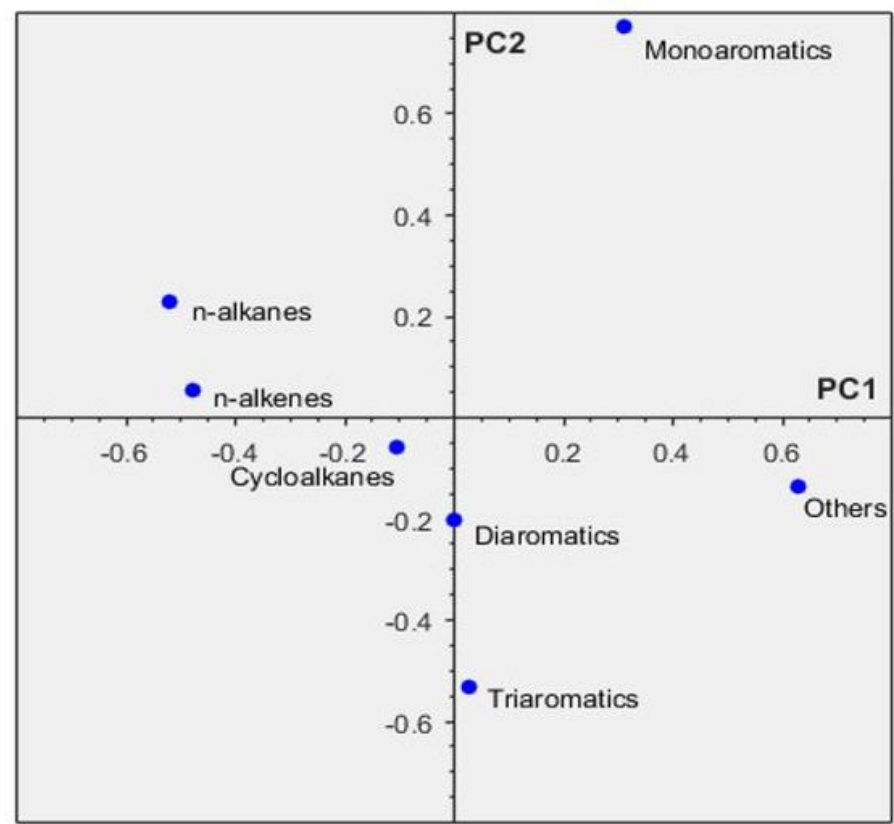

(b)

Figure 8

Scores Plot (a) and Loadings Plot (b) excluding the Neyveli Lignite

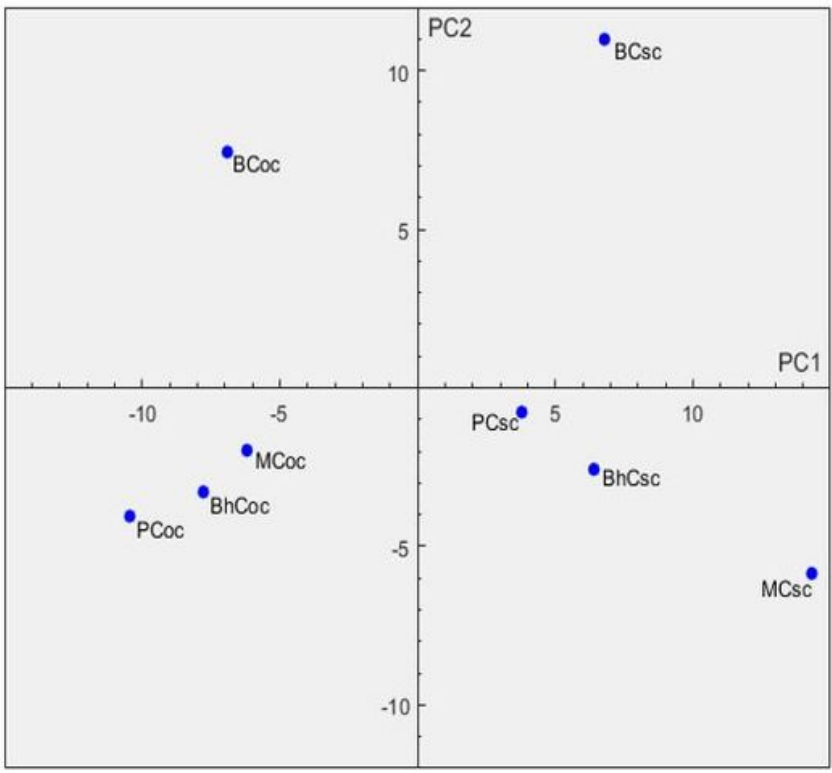

(a)

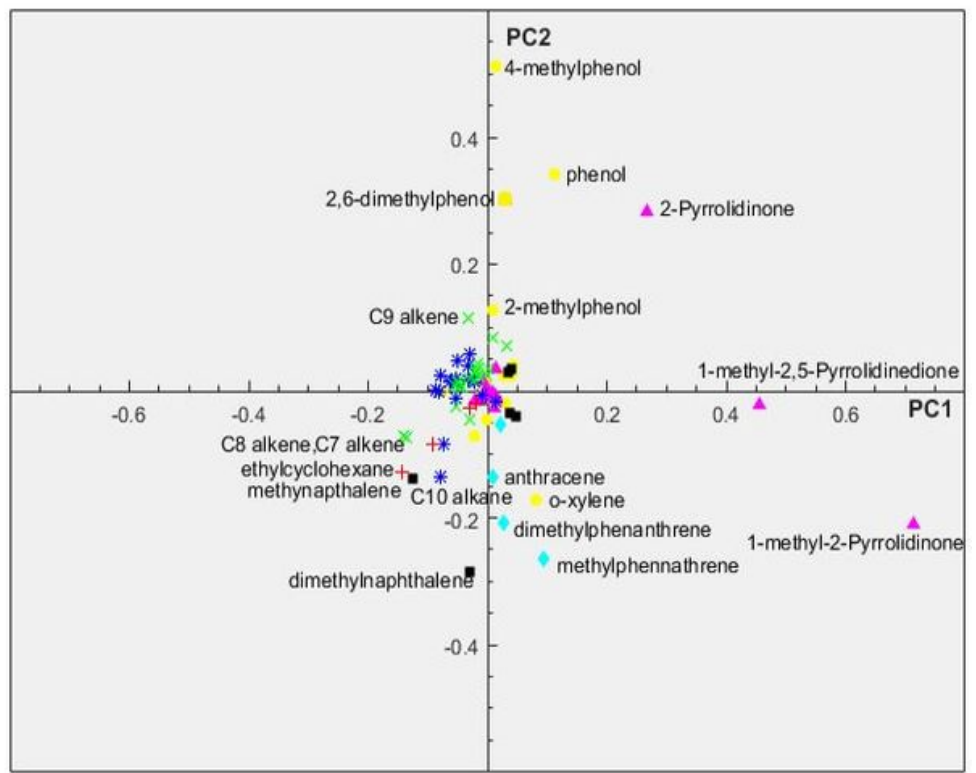

(b)

\section{Figure 9}

PCA Scores Plot (a) and Loadings Plot (b) including all compounds (LBlue Asterix - Alkanes; Red Plus-CycloAlkanes; Green Cross - Alkenes; Yellow Dot-Monoaromatics; Black Squares -Diaromatics; Cyan Diamonds- Triaromatics; Magenta Triangle-Others.) 


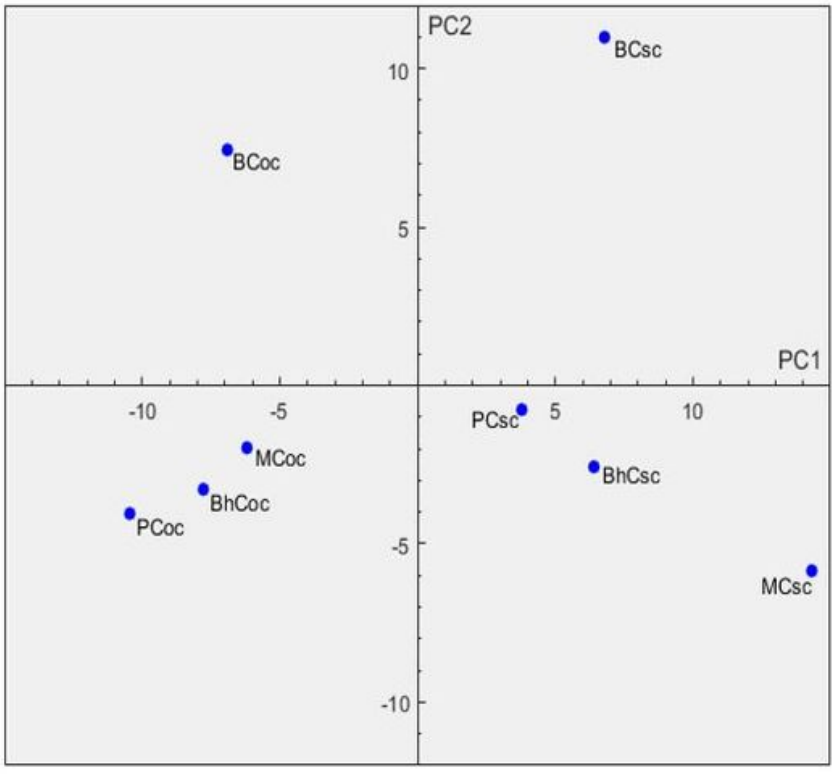

(a)

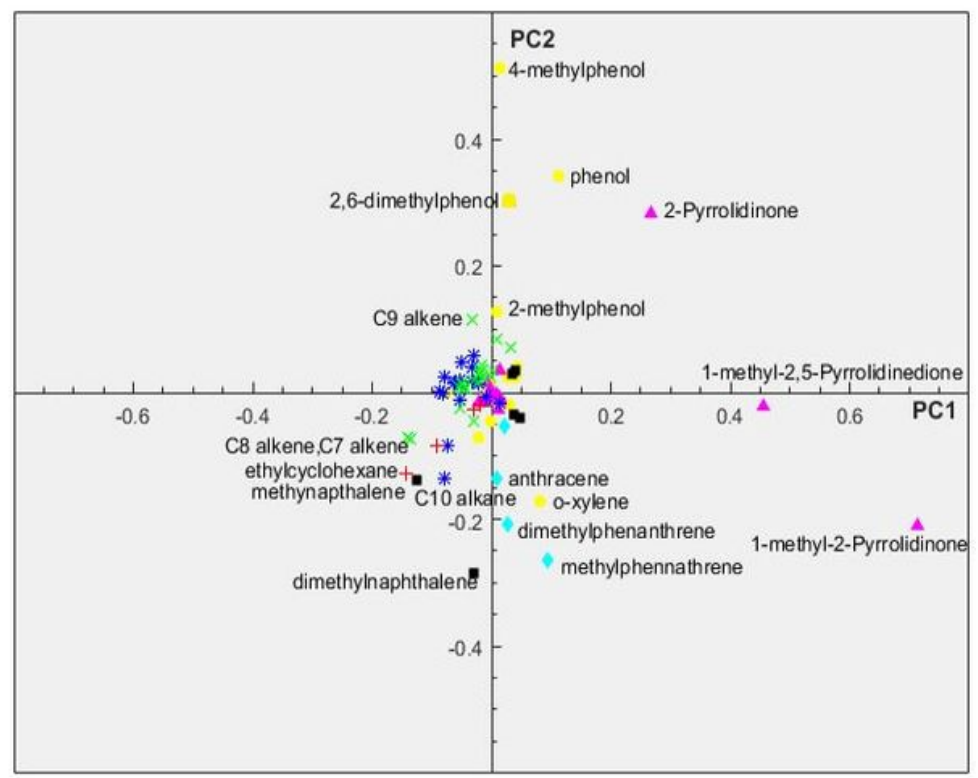

(b)

\section{Figure 9}

PCA Scores Plot (a) and Loadings Plot (b) including all compounds (LBlue Asterix - Alkanes; Red Plus-CycloAlkanes; Green Cross - Alkenes; Yellow Dot-Monoaromatics; Black Squares -Diaromatics; Cyan Diamonds- Triaromatics; Magenta Triangle-Others.)

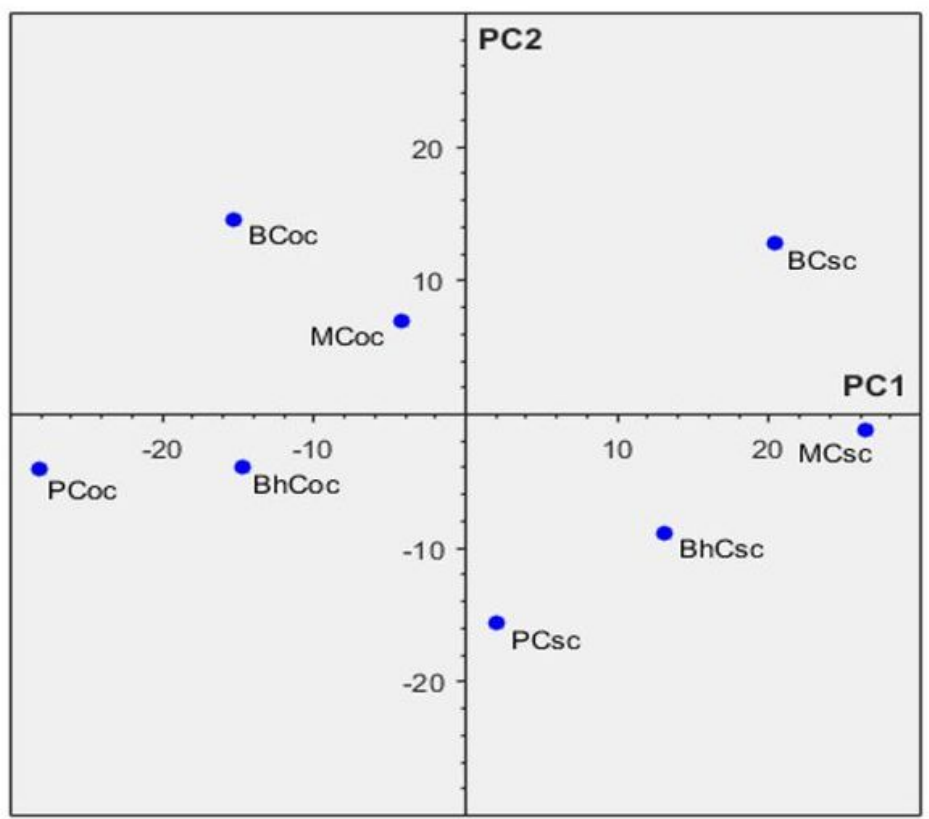

(a)

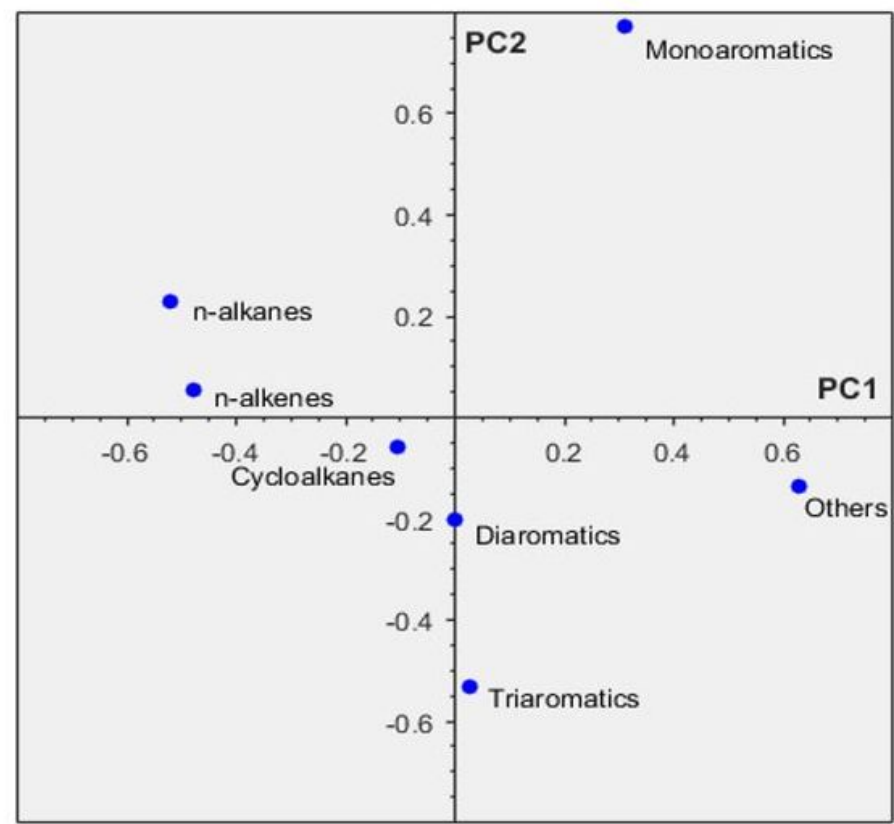

(b)

Figure 9

Scores Plot (a) and Loadings Plot (b) excluding the Neyveli Lignite 


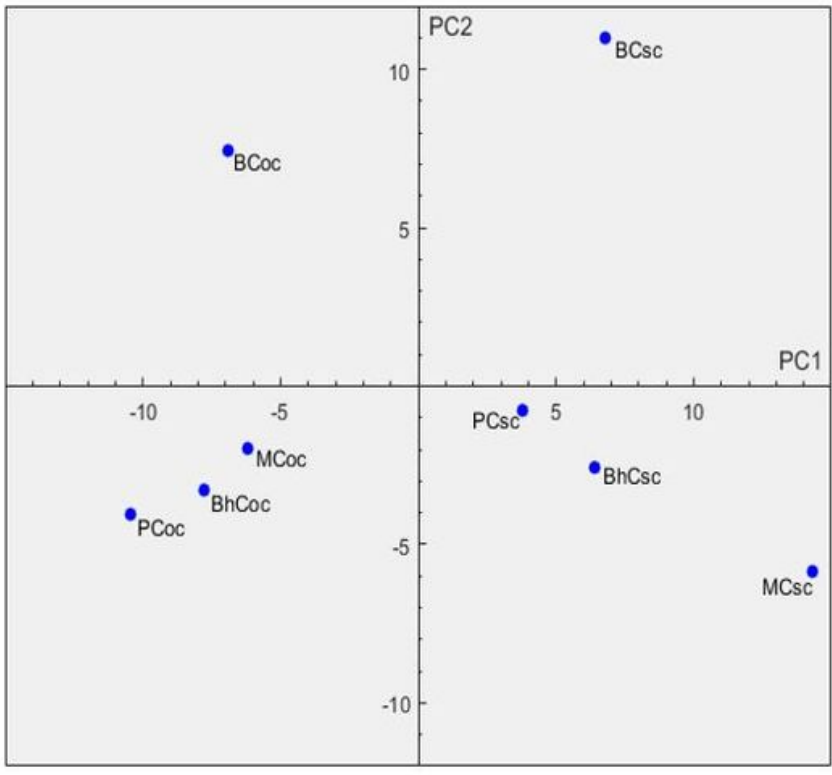

(a)

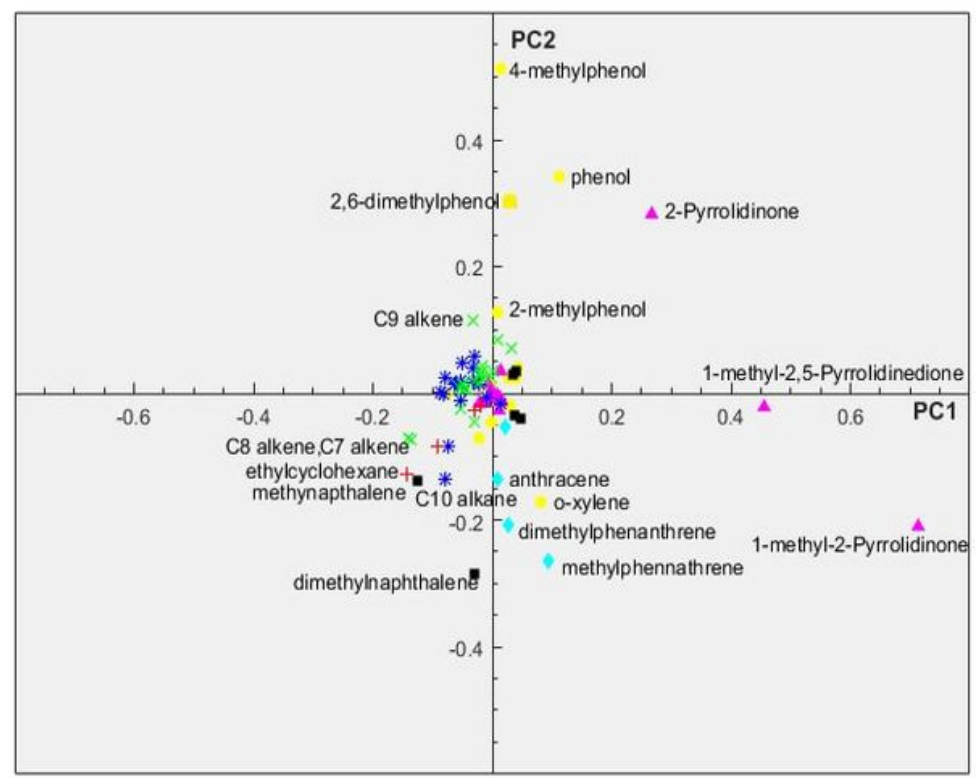

(b)

\section{Figure 10}

PCA Scores Plot (a) and Loadings Plot (b) including all compounds (LBlue Asterix - Alkanes; Red Plus-CycloAlkanes; Green Cross - Alkenes; Yellow Dot-Monoaromatics; Black Squares -Diaromatics; Cyan Diamonds- Triaromatics; Magenta Triangle-Others.)

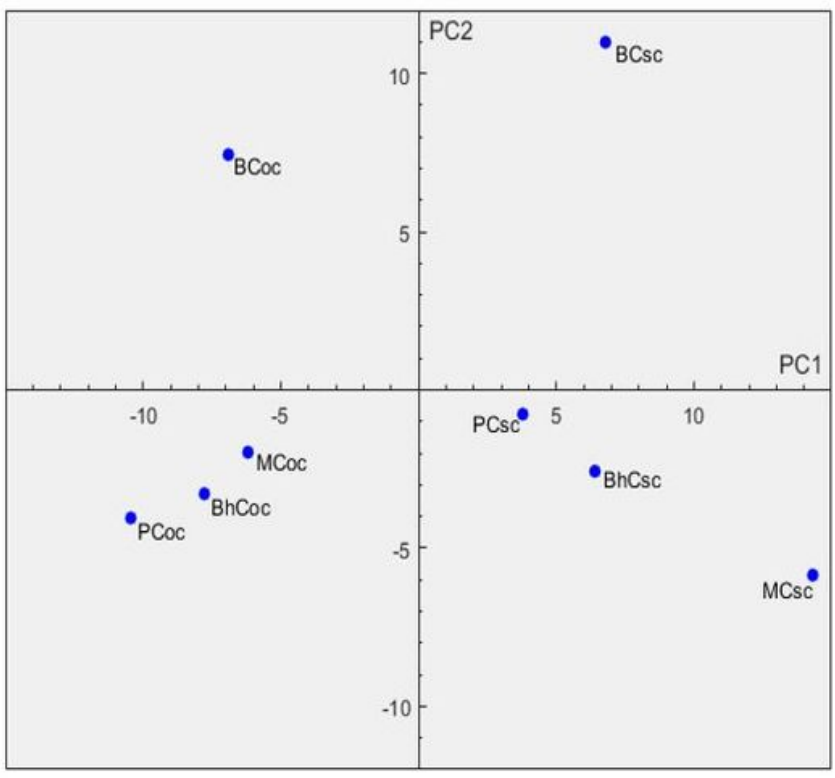

(a)

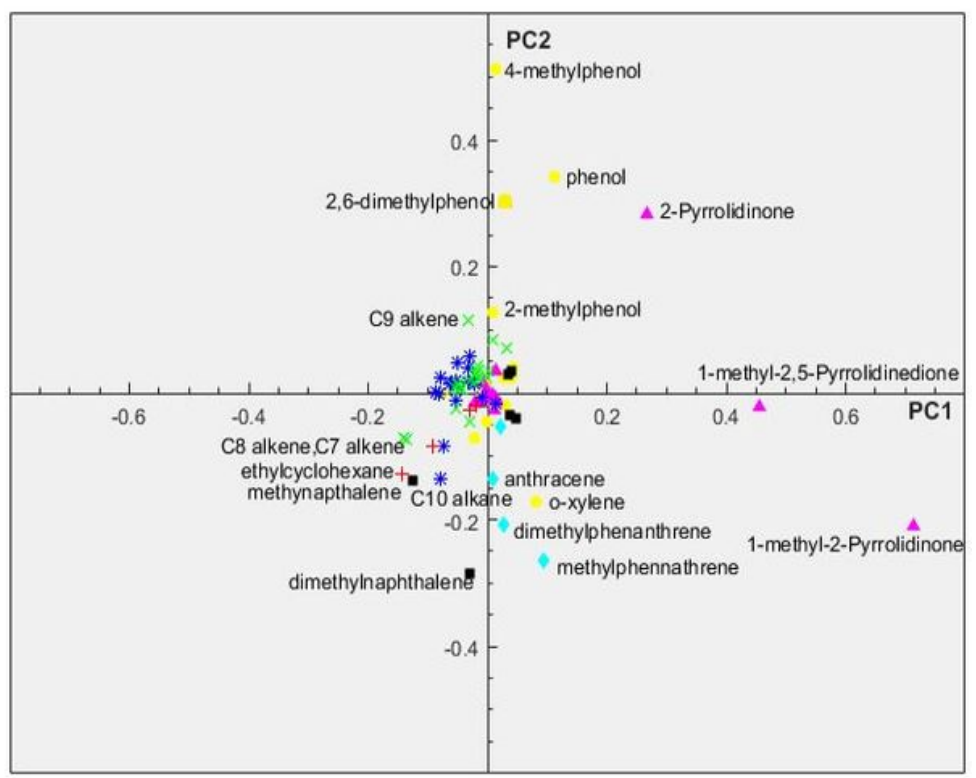

(b)

Figure 10

PCA Scores Plot (a) and Loadings Plot (b) including all compounds (LBlue Asterix - Alkanes; Red Plus-CycloAlkanes; Green Cross - Alkenes; Yellow Dot-Monoaromatics; Black Squares -Diaromatics; Cyan Diamonds- Triaromatics; Magenta Triangle-Others.) 


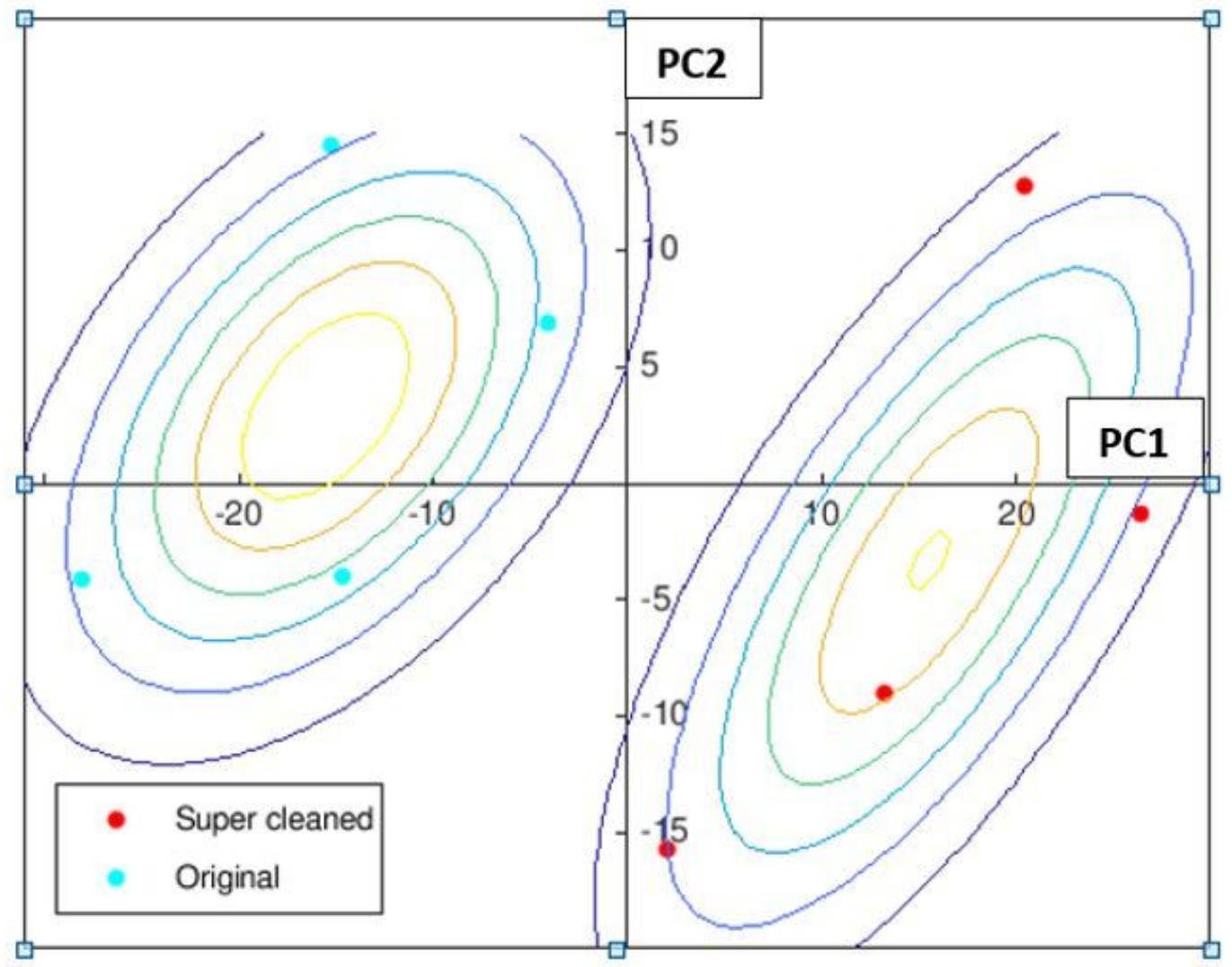

Figure 11

Gaussian Contour Plot (excluding Neyveli lignite samples)

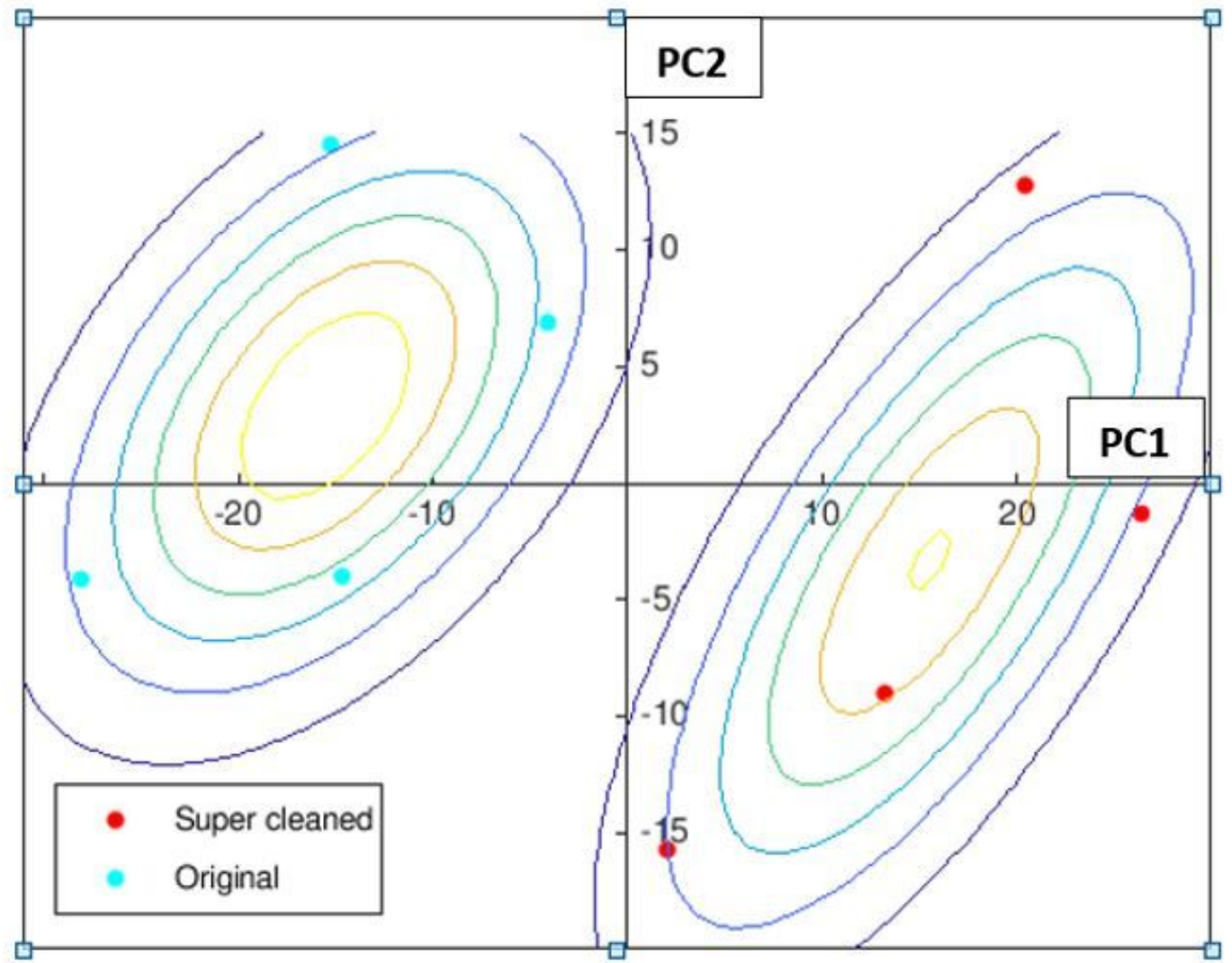


Figure 11

Gaussian Contour Plot (excluding Neyveli lignite samples)

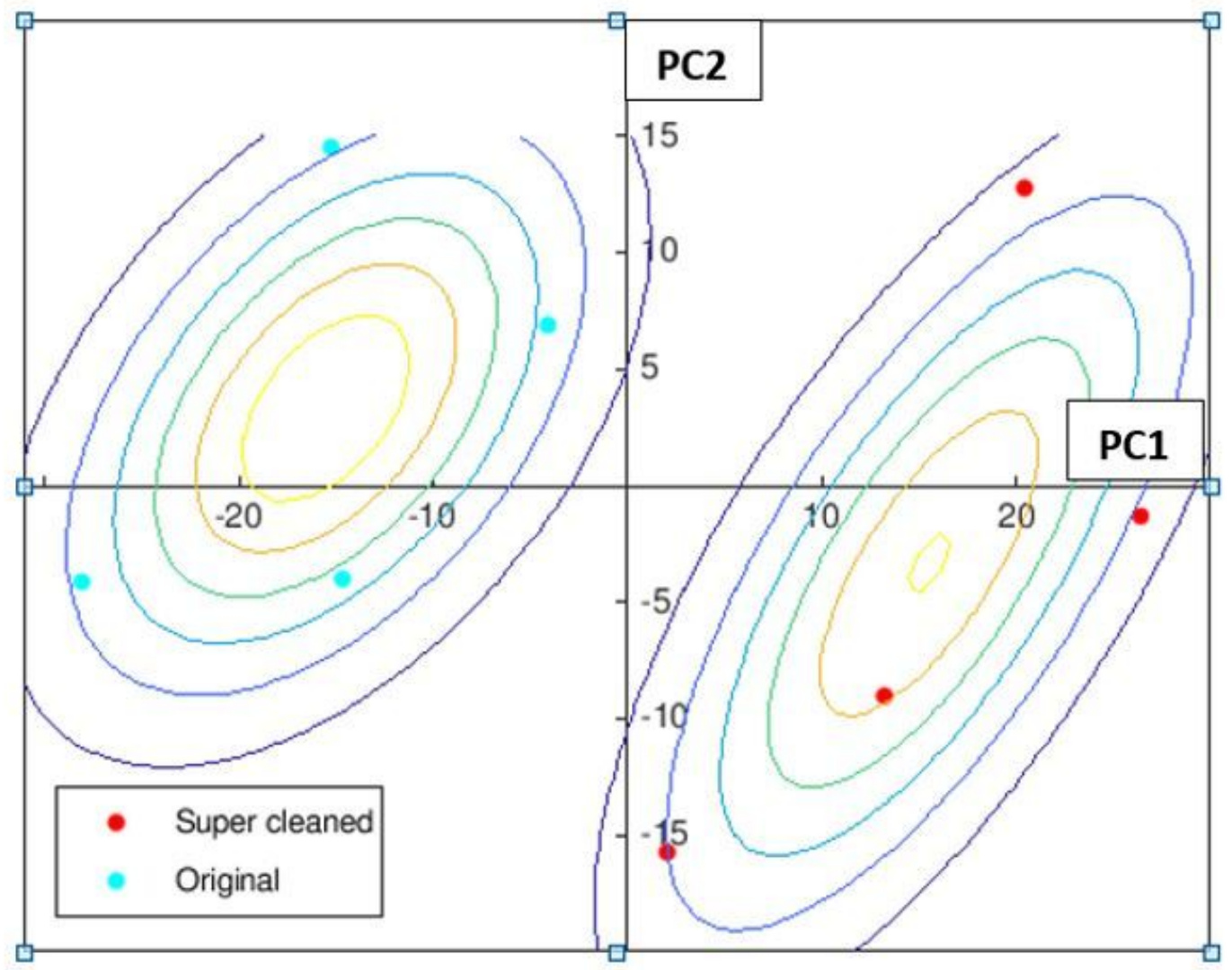

Figure 12

Gaussian Contour Plot (excluding Neyveli lignite samples) 


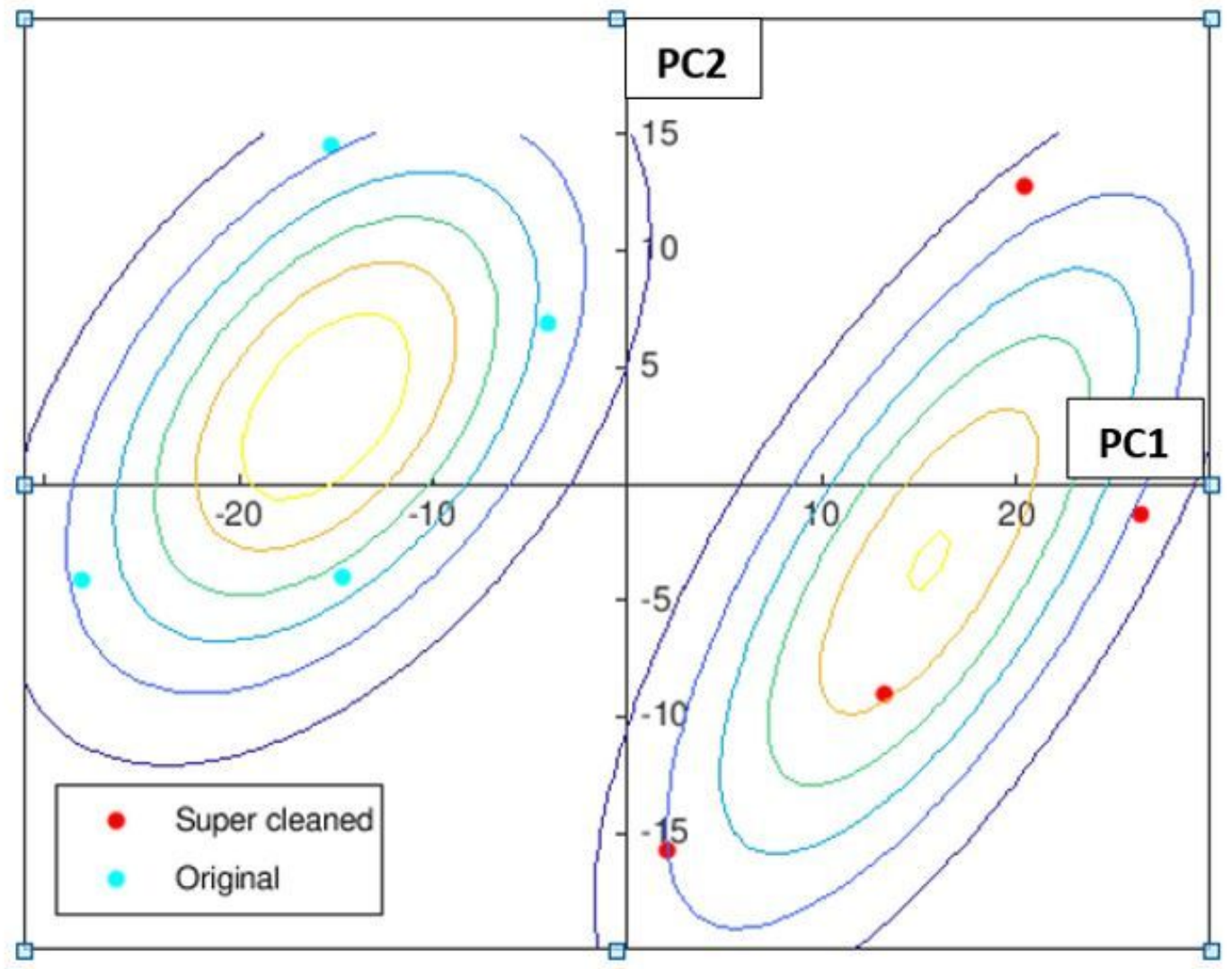

Figure 12

Gaussian Contour Plot (excluding Neyveli lignite samples) 